\title{
ALLELOPATHIC POTENTIAL \\ OF \\ CYPERUS ROTUNDUS L.
}

BY

JAMES PRESTON GILREATH

A DISSERTATION PRESENTED TO THE GRADUATE COUNCIL OF THE UNIVERSITY OF FLORIDA IN PARTIAL FULFILLMENT OF THE REQUIREMENTS FOR THE DEGREE OF DOCTOR OF PHILOSOPHY

UNIVERSITY OF FLORIDA

1981 
Dedicated

In

Loving Memory

To

my grandmother, Mae Bolt Charles

from whom I learned my

love for plants. 


\section{ACKNOWLEDGEMENTS}

The author wishes to express his sincere appreciation to Dr. S. J. Locascio, chairman of the supervisory committee, for his assistance and friendship during the course of these studies and during the preparation of this manuscript.

The assistance of the other committee members, Dr. C. B. Ha11, Dr. M. Wilcox, Dr. N. Gammon, especially Dr. S. R. Kostewicz and Dr. D. J. Cantliffe, is gratefully acknowledged.

Sincere appreciation is extended to Dr. R. H. Biggs for his assistance and provision of the HPLC used in this work.

The author wishes to acknowledge and thank Dr. L. C. Hannah for making available the equipment used in the gel chromatography study.

Special thanks is also extended to Dr. D. A. Graetz and Candy Cantlin for their assistance in certain portions of the author's work.

The author would like to acknowledge Dr. R. W. King for the mass spectrometric analysis performed.

Genuine appreciation is extended to Maria Antigua and Mike Alligood for assistance they provided.

Above a11, the author offers his love, affection and thanks to his parents, Margaret C. Gilreath and Charles E. Gilreath and his brother, Major Charles E. Gilreath, Jr., whose moral support and personal and financial sacrifices 
throughout his college years made his educational dreams a reality. The author also wishes to express his appreciation, love and devotion to his wife, Phyllis Anne Robinson Gilreath, for her unselfish assistance and constant devotion through their graduate years.

Last, but not least, the author wishes to acknowledge all the little people who make life worth living . . thanks Horatio, Charlie and Susie. 


\section{TABLE OF CONTENTS}

Page

ACKNOWLEDGEMENTS ..................... ii

LIST OF TABLES $\ldots \ldots \ldots \ldots \ldots \ldots \ldots \ldots \ldots \ldots \ldots \ldots \ldots \ldots \ldots \ldots \ldots$

LIST OF FIGURES........................ xii

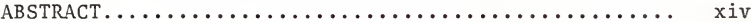

INTRODUCTION........................... 1

REVIEW OF LITERATURE...................... 3

MATERIALS AND METHODS...................... 10

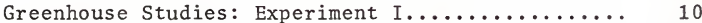

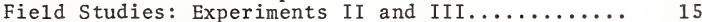

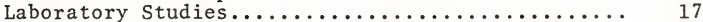

Bioassays--Experiments IV and V..................... 17

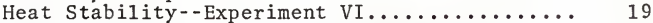

Water Solubility--Experiment VII........... 20

Ge1 Chromatography--Experiment VIII.......... 21

Mass Spectrometric Analysis--Experiment IX.... 22

High Pressure Liquid Chromatography--

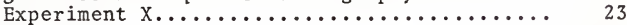

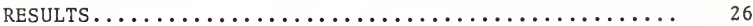

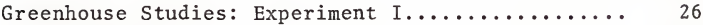

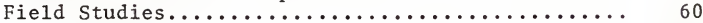

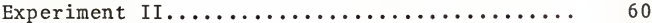

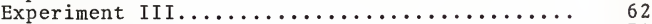

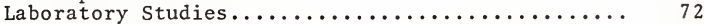

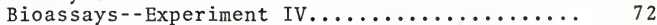

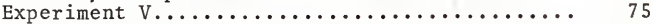

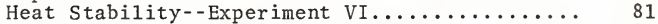

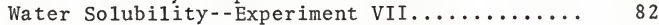

Ge1 Chromatography--Experiment VIII......... 86

Mass Spectrometric Analysis--Experiment IX.... 90

High Pressure Liquid Chromatography--

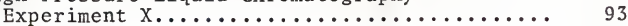

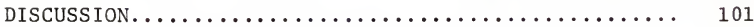

Greenhouse Studies: Experiment I............................ 101

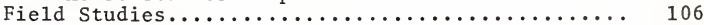

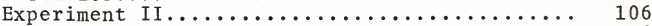

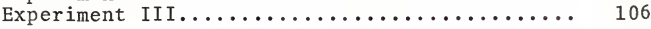


Laboratory Studies: Experiments IV-X......... 108

SUMMARY AND CONCLUSIONS................... 113

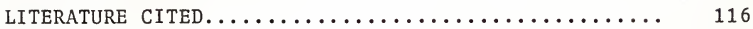

BIOGRAPHICAL SKETCH..................... 121 
1. C. rotundus material applied to upper crock seed

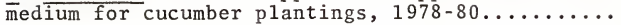

2. C. rotundus material applied to upper crock seed medium for lettuce and tomato plantings, 1979-

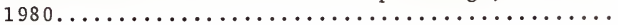

3. Planting and harvest dates and seeding rates for bioassay crops in greenhouse experiments, 1978-

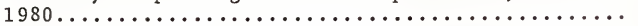

4. Mean squares for the analysis of variance of the effect of $C$. rotundus material in upper crock medium on growth of cucumber planted on May 19, 1978, in upper and lower crocks (planting number 1)....

5. Effect of $\mathrm{C}$. rotundus material in upper crock medium on growth of cucumber planted on May 19, 1978, in upper and lower crocks (planting number 1)....

6. Mean squares for the analyses of variance of the effect of $\mathrm{C}$. rotundus material in upper crock medium on growth of cucumber planted on May 30, 1978, in upper and lower crocks (planting number 2)... 30

7. Effect of $\mathrm{C}$. rotundus material in upper crock medium on growth of cucumber planted on May 30,1978 , in upper and lower crocks (planting number 2)....

8. Mean squares for the analyses of variance of the effect of $\mathrm{C}$. rotundus material in upper crock medium on growth of cucumber planted on June 30 , 1978 , in upper and lower crocks (planting number

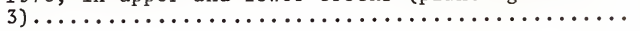

9. Effect of $\underline{C}$. rotundus material in upper crock medium on growth of cucumber planted on June 30 , 1978 , in upper and lower crocks (planting number

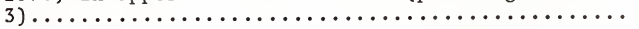

10. Mean squares for the analyses of variance of the effect of $\mathrm{C}$. rotundus material in upper crock medium on growth of cucumber planted on September 19, 1978 , in upper and lower crocks (planting number 4) 
11. Effect of C. rotundus material in upper crock medium on growth of cucumber planted on September 19, 1978 , in upper and lower crocks (planting number

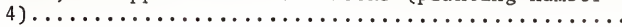

12. Mean squares for the analyses of variance of the effect of $\underline{C}$. rotundus material in upper crock medium on growth of cucumber planted on January 11, 1979 , in upper and lower crocks (planting number

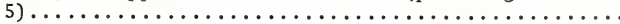

13. Effect of $\underline{C}$. rotundus material in upper crock medium on growth of cucumber planted on January 11, 1979 , in upper and lower crocks ( 1 lanting number

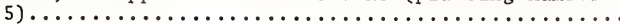

14. Mean squares for the analyses of variance of the effect of $\underline{C}$. rotundus material in upper crock medium on growth of cucumber planted on September 13, 1979, in upper and lower crocks (planting number

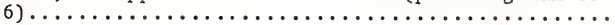

15. Effect of $\underline{C}$. rotundus material in upper crock medium on growth of cucumber planted on September 13, 1979 , in upper and lower crocks (planting number

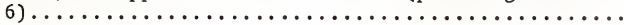

16. Mean squares for analyses of variance of the effect of $\underline{C}$. rotundus material in upper crock medium on growth of cucumber planted on October 29, 1979, in upper and lower crocks (planting number 7)

17. Effect of $\underline{\text { C. }}$ rotundus material in upper crock medium on growth of cucumber planted on October 29, 1979, in upper and lower crocks (planting number

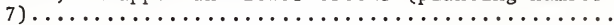

18. Mean squares for the analyses of variance of the effect of $\underline{C}$. rotundus material in upper crock medium on growth of cucumber planted on January 18 , 1980 , in upper and lower crocks (planting number 8)

19. Effect of C. rotundus material in upper crock medium on growth of cucumber planted on January 18 , 1980 , in upper and lower crocks (planting number 8) 
Table

20. Mean squares for the analyses of variance of the effect of $\underline{C}$. rotundus material in upper crock medium on growth of lettuce planted on January 28 , 1979, in upper and lower crocks (planting number

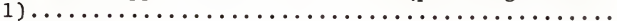

21. Effect of $\underline{C}$. rotundus material in upper crock medium on growth of lettuce planted on January 28 , 1979, in upper and lower crocks (planting number

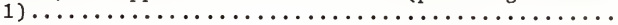

22. Mean squares for the analyses of variance of the effect of $\underline{C}$. rotundus material in upper crock medium on growth of lettuce planted on April 5, 1979, in upper and lower crocks (planting number

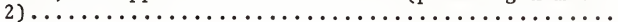

23. Effect of $\underline{\text { C. }}$ rotundus material in upper crock medium on growth of lettuce planted on April 5, 1979, in upper and lower crocks (planting number

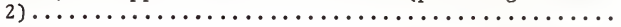

24. Mean squares for the analyses of variance of the effect of $\underline{C}$. rotundus material in upper crock medium on growth of tomato planted on April 9, 1979, in upper and lower crocks (planting number 1)

25. Effect of $\underline{C}$. rotundus material in upper crock medium on growth of tomato planted on April 9, 1979, in upper and lower crocks (planting number 1)

26. Mean squares for the analyses of variance of the effect of $\mathrm{C}$. rotundus material in upper crock medium on growth of tomato planted on May 10, 1979, in upper and lower crocks (planting number 2)....

27. Effect of $\underline{C}$. rotundus material in upper crock medium on growth of tomato planted on May 10, 1979, in upper and lower crocks (planting number 2)....

28. Correlations between $\underline{C}$. rotundus densities and densities of other weed species...............

29. Mean squares for the analyses of variance of the effects of $\underline{C}$. rotundus tubers and tuber extract on number and growth of radish, cucumber, tomato and lettuce plants in field plots, October 15, 1979 . 
30. Effects of $\underline{C}$. rotundus tubers and tuber extract on number añ growth of radish, cucumber, tomato and lettuce in field plots, October 15, 1979.....

31. Mean squares for the analyses of variance of the effects of $\mathrm{C}$. rotundus tubers and tuber extract on number añd weight of plants of 7 weed species in field plots, October 15, 1979............

32. Effect of $\mathrm{C}$. rotundus tubers and tuber extract on number and weight of plants of 7 weed species in field plots, October 15, 1979............

33. Mean squares for the analyses of variance of the effect of $\mathrm{C}$. rotundus tubers and tuber extract on number and weight of plants of radish, cucumber, tomato and lettuce in field plots, November

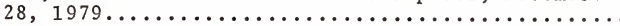

34. Effect of $\mathrm{C}$. rotundus tubers and tuber extract on number and weight of plants of radish, cucumber, tomato and lettuce in field plots, November

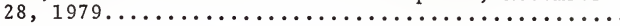

35. Mean squares for the analyses of variance of the effect of $\mathrm{C}$. rotundus tubers and tuber extract on number and weight of plants of 7 weed species in field plots, November $28,1979 \ldots \ldots \ldots \ldots \ldots \ldots$.

36. Effect of $\mathrm{C}$. rotundus tubers and tuber extract on number and weight of plants of 7 weed species in field plots, November $28,1979 \ldots \ldots \ldots \ldots \ldots \ldots$

37. Mean squares for the analyses of variance of the influence of $\mathrm{C}$. rotundus tissue extract on cucum-

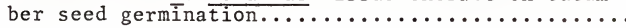

38. Influence of $\mathrm{C}$. rotundus tissue extracts on

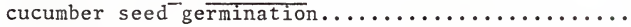

39. Mean squares for the analyses of variance of the influence of $C$. rotundus tuber extract on cucum-

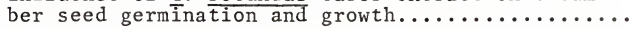

40. Influence of $\mathrm{C}$. rotundus tuber extract on cucum-

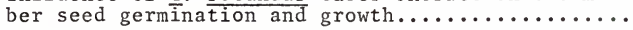

41. Mean squares for the analyses of variance of the effect of leachates and extract of media infested with $\underline{C}$. rotundus on seed germination and growth

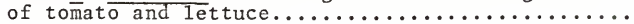


Table

42. Effect of leachates and extract of media infested

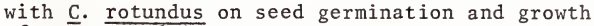

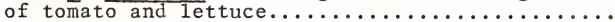

43. Mean squares for the analyses of variance of the influence of heat on biological activity of $\underline{C}$. rotundus tuber extract as measured by cucumber

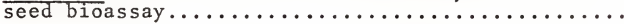

44. Influence of heat on biological activity of $\underline{C}$. rotundus tuber extract as measured by cucumber

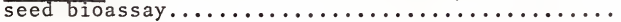

45. Mean squares for the analyses of variance of the influence of the water soluble fraction of $\underline{C}$. rotundus tuber extract on cucumber seed germina-

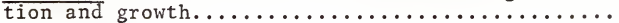

46. Influence of the water soluble fraction of $\mathrm{C}$. rotundus tuber extract on cucumber seed germina-

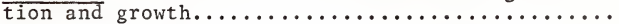

47. Mean squares for the analyses of variance of the effect of four concentrations of protocatechuic and linoleic acids, alone and in combination, on

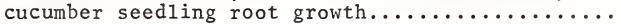

48. Effect of four concentrations of protocatechuic and linoleic acids, alone and in combination, on

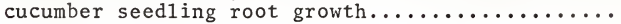

49. Mean squares for the analysis of variance of the effect of fractions of $\mathrm{C}$. rotundus tuber extract eluted from a silica car̂tridge (Sep-pak) on cucum-

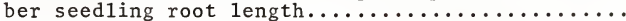

50. Effect of fractions of $\mathrm{C}$. rotundus tuber extract eluted from a silica cartridge (Sep-pak) on cucum-

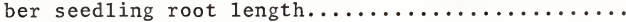

51. Mean squares for the analyses of variance of the effect of fractions of $\mathrm{C}$. rotundus tuber extract separated by liquid chromatography on cucumber

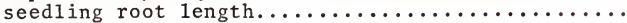

52. Effect of fractions of $\mathrm{C}$. rotundus tuber extract separated by liquid chromatography on cucumber

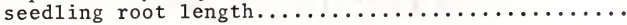


53. Mean squares for the analyses of variance of the effect of diluted fractions of $\mathrm{C}$. rotundus tuber extract eluted from a silica cartridge (Sep-pak)

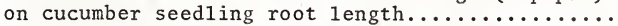

54. Effect of diluted fractions of C. rotundus tuber extract eluted from a silica cartridge (Sep-pak) on cucumber seedling root length...................... 100 


\section{LIST OF FIGURES}

Figure

Page

1. Molecular weight calibration curve for Sephadex LH-20 ge1 column......................

2. Elution profile for inhibitors eluted from

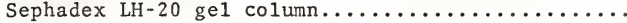


Abstract of Dissertation Presented to the Graduate Council of the University of Florida in Partial Fulfillment of the Requirements for the Degree of Doctor of Philosophy

\title{
Allelopathic Potential of Cyperus rotundus L.
}

\author{
By \\ James Preston Gilreath \\ March, 1981
}

Chairman: Dr. S. J. Locascio

Major Department: Horticultural Science

The allelopathic effects of leachates from Cyperus rotundus L. (purple nutsedge) plants and tissue residues were studied in greenhouse sand culture experiments at Gainesville, Florida. Cucumber (Cucumis sativus L.), lettuce (Lactuca sativa L.) and tomato (Lycopersicon esculentum Mill.) were used as bioassay plants. Growth of bioassay species was reduced by leachates from growing nutsedge plants, decaying leaves and tubers with the greatest reduction from growing nutsedge plants. A seasonal variation in results was noted with maximum growth reduction occurring in fall and winter studies.

Density of $\underline{C}$. rotundus in a field was correlated negatively with density of Richardia scabra L. and positively 
correlated with densities of Euphorbia hirta L. and Geranium carolinianum L.

A study was conducted to evaluate tubers and $\mathrm{CH}_{3} \mathrm{OH}$ extracts of tubers as phytotoxins under field conditions. Bioassay crops were cucumber, tomato, radish (Raphanus sativus L.) and lettuce. Plant density and weight were also obtained for 7 weed species. Soil incorporation of nutsedge tuber extract reduced the no. of cucumber, Eleusine indica (L.) Gaertn. and Digitaria sanguinalis (L.) Scop. plants as compared to the no. in the control treatment. Nutsedge tubers incorporated into the soil (Aeric Haplaquod) reduced the weight of Raphanus raphanistrum L. plants relative to the control.

Laboratory studies were conducted to determine if purple nutsedge tubers contained an allelopath and to chemically separate and characterize the compound(s) in tubers. Cucumber seed germination bioassays indicated the presence of a growth inhibitor in $\mathrm{CH}_{3} \mathrm{OH}$ extracts of purple nutsedge tubers and the presence of an inhibitor in $\mathrm{CH}_{3} \mathrm{OH}$ extracts of soil in which purple nutsedge had previously grown. The allelopath was shown to be heat stable and water soluble with an approximate molecular weight of $250 \mathrm{amu}( \pm 100 \mathrm{amu})$ as determined by gel chromatography.

Mass spectrometric analysis of a combined sample of the 3 most active separates obtained by gel chromatography suggested constituents included protocatechuic and linoleic acids. 
Further separation of the allelopathic compound(s) from interfering compounds was attempted by high pressure liquid chromatography preceded by a separation procedure based on elution by a solvent sequence of increasing polarity. The allelopath consisted of 2 or more compounds, one of which was low in polarity, while the other was fairly polar. Attempts to further separate these components by high pressure liquid chromatography were not successful. It is suggested that the allelopath may actually be a complex of compounds that are water soluble, heat stable and have molecular weights of approximate1y $250 \pm 100 \mathrm{amu}$. 


\section{INTRODUCTION}

Cyperus rotundus L. (purple nutsedge) is considered to be the world's worst weed. It is often found as sizeable infestations in vegetable and agronomic fields. Changes in cultural practices and the increased use of herbicides which reduce the number of controlled weeds and thus decrease their competitive ability have resulted in purple nutsedge and other "resistant" species infesting larger acreages (60).

C. rotundus may be controlled to varying degrees by cultural and chemical means. Both methods have limitations. Cultural control results in incorporation of large quantities of plant tissues into the soil and can lead to larger infestations as tuber chains are broken, releasing tubers from dormancy imposed by apical dominance, and tubers are spread about the field (46). Chemical control is limited by the availability of herbicides which are both effective against nutsedge and registered for use on a given crop. Herbicides which are effective against nutsedge are often phytotoxic to the crop or have residual periods which determine what crops can be grown after application of the compound. This is especially true with vegetable crops as the choice of compounds is often not as great as with agronomic crops. Chemical and cultural control both eventually result in addition of large quantities of plant debris to the soil environment. These tissue residues might result in a significant yield reduction for the grower if they release allelopathic compounds. 
Interference with plant growth by competition and production of allelopathic compounds has been ascribed to many plants including annual crops, trees and weeds $(1,2,6,12$, $18,22,23,24,34,37,40,48)$. Competitive effects of $\underline{\mathrm{C}}$. rotundus are well known $(58,59,60)$, but less is known about its allelopathic potential. Most information which is available concerns growth reductions due to decaying tissues ( 10 , 16) and water extracts of tubers (45) which may involve anaerobic decay by-products. None of this information proves that the allelopathic compound is produced directly by $\underline{\mathrm{C}}$. rotundus plants.

The experiments reported here were designed to evaluate the a1lelopathic potential of growing and decaying $\underline{C}$. rotundus, determine whether its cultural and chemical control poses a significant problem with regard to possible allelopaths released by decaying tissues, and to chemically characterize the compound(s) involved. 


\section{REVIEW OF LITERATURE}

Many plants have been shown to produce chemicals that will reduce the growth and development of other plants. These compounds are called allelopaths and the chemical interaction between plants is allelopathy. The term "allelopathy," originally coined in 1937 by Molisch (31), referred to both beneficial and adverse chemical interactions between plants. It has since been modified by Rice (43) to pertain only to adverse chemical effects. Allelopathic interactions are often thought to be restricted to higher plants, but they may also involve lower plants and microorganisms, both alone and in various combinations. An allelopathic effect is dependent upon the addition of a chemical compound to the environment by a plant; whereas, competition involves the removal of something from the habitat. Thus, one should think of allelopathy and competition as being 2 distinct phenomena under the general heading of interference.

The earliest known written reference to allelopathy is contained in a 300 year old Japanese document (44). It states that water washings of leaves of Pinus densiflora Sieb. and Zucc. were injurious to crops growing under this tree. The classic example of allelopathy is the wilting of tomato plants grown in close proximity to black walnut trees (Juglans nigra L.) (6). Most of the scientific evidence for allelopathy was not obtained until the 20 th century with the vast majority of 
the information appearing after 1960 (44). Thus, the study of allelopathy is a relatively young discipline.

Allelopaths have been found in all plant parts, excluding the hypocotyl. Roots have been shown to contain allelopaths which in some cases, such as with black walnut trees (26), require root contact between 2 species, while in other instances allelopathic root exudates have been produced (5).

Bode (4) demonstrated inhibitory activity of leaf leachates from wormwood (Artemisia absinthium L.). Allelopathic activity of leaf and stem residues has been observed for many plants, including wheat straw (Triticum spp. L.) (27), wormwood (11), timothy (Phleum pratense L.), corn ( rye (Secale cereale L.), and tobacco (Nicotiana tabacum L.) (41). Still et al. (49) found that extracts of silver maple (Acer saccharinum L.) bark contained a phenolic inhibitor. Flowers have also been shown to release allelopaths (43). Annual sunflowers (Helianthus annuus L.) produce floral compounds which are toxic to their own and other seedlings. As a result, in old-field succession, needlegrass (Aristida oligantha Michx.) was established as the dominant species (61). Harborne and Simmonds (13) found catechol in the fruit of Citrus spp. L. A number of researchers have reported germination inhibitors released by various seeds $(12,18,51)$.

Allelopaths are released to the environment by 5 main means: 1) root exudation (5), 2) direct tissue contact (26), 3) leachates from various tissues $(4,11,27)$, 4) volatilization $(33,34,35,36,37,38)$, and 5) through decay $(41,48)$. 
Rice (43) classified allelopaths in 15 categories as follows: 1) water soluble organic acids, straight-chain alchohol, aliphatic aldehydes, and ketones, 2) simple unsaturated lactones, 3) long-chain fatty acids, 4) naphthoquinones, anthraquinones, and complex quinones, 5) terpenoids and steroids, 6)simple phenols, benzoic acid, and various derivatives, 7) cinnamic acid and derivatives, 8) coumarins, 9) flavonoids, 10) tannins, 11) amino acids and polypeptides, 12) alkaloids and cyanohydrins, 13) sulfides and mustard oil glycosides, 14) purines and nucleosides, and 15) miscellaneous compounds, including abscisic acid. The most frequently identified allelopaths produced by higher plants have been phenols and benzoic and cinnamic acids and their derivatives (43)

Allelopathy is important not only with regard to direct effects on higher plants, but also through indirect effects due to changes in the soil microbial population, resulting in alterations in the nutritional status of the soil and unfavorable shifts in the microflora. Important examples are changes in the population of nitrifying bacteria, Nitrosomonas spp. and Nitrobacter spp. A decrease in their population would result in a decrease in nitrate $\left(\mathrm{NO}_{3}{ }^{-}\right)$nitrogen available for plant growth, and an increase in ammonium $\left(\mathrm{NH}_{4}{ }^{+}\right)$nitrogen. Plants are generally able to utilize either of these ionic forms of $\mathrm{N}$; however, some plant species achieve better growth with one form than with the other (56). Thus, the negative influence of an allelopathic agent on nitrifying 
bacteria might be manifested as a nutritional disorder of the affected plants or reduced growth. The inhibition of nitrification by allelopathy has been reviewed by Rice (43). This inhibition is widespread, and occurs as a result of forests $(7,17,21)$, crop plants $(8,28,30,32,54)$ and weed species, both broadleaved and grasses $(29,42)$.

C. rotundus, a sedge, belongs to the family Cyperaceae. It can be distinguished in the field from $\underline{C}$. esculentus L. by the production of tuber chains along stolons, whereas, C. esculentus produces stolons which terminate in tubers (9). In addition, these species have different geographical limitations. C. rotundus is restricted to tropical, subtropical and temperate climates where the soil seldom freezes, and C. esculentus can thrive in cooler regions $(15,50)$.

The principal method of propagation of $\underline{\mathrm{C}}$. rotundus is by basal bulbs and tubers (53). The importance of reproduction by seed is questionable as conflicting results in seed germination have been reported (55). The reproductive capacity of $\underline{C}$. rotundus tubers is quite high, i.e. up to 1,200 new shoots and tubers from 1 tuber in 20 weeks. The underground structures generally weigh 4 to 5 times more than the foliage (14). Betria and Montaldi (3) observed that maximum tuber formation in Argentina occurred in fall and winter and dropped to a minimum in spring and summer. Allelopathic information on $\underline{C}$. rotundus is limited to decaying residues and tuber extracts $(10,16,45)$. Friedman and Horowitz (10) demonstrated a reduction in radicle length 
of barley (Hordeum distichum L. cv. 'Esperanza'), black mustard (Brassica spp. L. cv. 'Alsace') and wheat (Triticum spp. L. $\mathrm{cv}$. 'Dwarf 68') when seeds were germinated in contact with water extracts of tissues of bermuda grass (Cynodon dactylon L.), C. rotundus and johnsongrass (Sorghum halepense L.), which had been allowed to decay in soil for 2 and 4 months. In a subsequent experiment, they employed the same technique but varied the duration of incubation for decay and the level of plant material in soil. They observed phytotoxic effects on barley (cv. 'Esperanza') for these same 3 species, both when the barley was sown directly in the soil and when a barley radicle length test of an ethanolic extract of soil was used (16).

The existence of natural phytotoxins in $\underline{\mathrm{C}}$. $\underline{\text { rotundus }}$ tissues was established by Singh (45). He used water extracts of tubers as the imbibition liquid for seed of a number of crops. He observed a reduction in percentage germination of seed of some crops, including peanuts (Arachis hypogaea L.), sesame (Sesamum indicum L.) and cowpeas (Vigna unguiculata (L.) Walp.). In addition, the percentage emergence and seedling length of these same crops and cotton (Gossypium spp. L.) were reduced.

Teo et al. (52) investigated bud inhibition of $\underline{\mathrm{C}}$. rotundus tubers. Using methanol, they extracted an inhibitory substance, referred to as inhibitor $\beta$, from tubers in the acidic ether fraction of the methanol. This substance 
inhibited spouting of excised buds of $\underline{\text { C. }}$ rotundus tubers and wheat coleoptile elongation. Thin layer chromatography studies suggested inhibitor $\beta$ consisted primarily of phenolic compounds with abscisic acid ( $A B A$ ) as a minor constituent. Torrey (57) confirmed the presence of $A B A$ in the inhibitor complex and identified cinnamic acid and meta- and para-coumaric acid as additional constituents. Although ABA was considered as the most potent component of the complex, not all of the inhibitory action of the complex was attributable to ABA. Although a number of compounds present in $\underline{\text { C. }}$ rotundus have been isolated and identified, none has been shown to be the allelopath responsible for the aforementioned growth reductions.

Komai and Ueki (19) isolated polyphenols from $\underline{\text { C. }}$ rotundus and identified them as catechol tannins, consisting primarily of leucoanthocyanin, which existed mainly as a form of leucocyanidin. The leucocyanidin content was high in rhizomes, seedheads, basal bulbs, and mature tubers with the highest quantities in the basal bulbs and mature tubers $(0.83 \mathrm{mg} / \mathrm{g}$ of mature tuber on a dry weight basis). Phenols are known to serve a regulatory role in IAA (indoleacetic acid) oxidation by IAA oxidase. Monophenols serve as cofactors for the enzyme, enhance the oxidation of IAA and result in inhibition of growth. 0-diphenolics act as inhibitors of IAA oxidase activity (20). Thus, leaching of phenols from $\underline{C}$. rotundus tissues could have an influence on the IAA oxidase activity of other biological systems in the 
zone of influence of these leachates. In addition to possible effects on IAA oxidase activity, phenolics, in general, are known to often be inhibitory to higher plants and microbes. 


\section{MATERIALS AND METHODS \\ Greenhouse Studies: Experiment I}

Greenhouse studies were conducted from 1978 to 1980 to determine if $\underline{\mathrm{C}}$. rotundus plants and residues reduced the growth of selected bioassay species by release of allelopathic compounds. A glass greenhouse located at the University of Florida Horticultural Research Unit near Gainesville, Florida was employed. All $\underline{\text { C. }}$ rotundus plants and residues used in this study were obtained from clonally propagated material. The experimental design was a randomized complete block with 4 replications. Each replicate consisted of a series of glazed clay crocks arranged in a stair-step fashion (43) with each upper crock draining into its respective lower crock which in turn drained into a foil covered 0.946 liter jar. The upper crocks measured $21 \mathrm{~cm}$ diameter $x 23 \mathrm{~cm}$ depth. The lower crocks were $24 \mathrm{~cm}$ diameter $\times 26 \mathrm{~cm}$ depth. One drain hole was provided at the bottom front of each crock. A rubber stopper fitted with a foil wrapped glass tube was inserted and the interior of the drain hole was packed with glass wool. The medium employed was sterile silica sand with a particle size range of 0.4 to $0.55 \mathrm{~mm}$. Nutrition was supplied by daily watering with half-strength Hoagland's No. 2 solution by applying 1 liter to each upper and lower crock. Leachate collected in the catch jar was divided into 2 equal portions and poured back into its respective upper and lower crocks to 
maintain uniform nutrition. The various treatments applied to the upper crocks are 1isted in Tables 1 and 2. Each upper and lower crock was seeded with various bioassay crops (Table 3). Once a stand was established, al1 crops were thinned to a final stand of 3 plants per crock. Before each planting the sand in the crocks was screened to remove organic matter and leached thoroughly with water. The glass catch jars were thoroughly washed before reusing. Each crock received the same treatment in each successive planting. Data were collected for various growth parameters such as percent emergence, emergence rate, plant diameter, length and fresh and dry weights and leaf area (lettuce). Leaf area was measured with a Mode1 L1-300 Li-Cor portable area meter. The average number of days required for emergence (emergence rate) was calculated by using the following equation modified from Maguire (25).

$$
\frac{\sum_{n=1}^{c} x_{n}(n)}{z}
$$

where $\mathrm{n}$ is the day on which emergence counts are made, $\mathrm{x}_{\mathrm{n}}$ is the number of plants emerging on day $n, c$ is the duration of the emergence test in days and $z$ is the total number of seedlings emerging over the entire period. Data were analyzed statiscally using the analysis of variance with treatment means ranked by Duncan's new multiple-range test (47). 
Table 1. C. rotundus material applied to upper crock seed medium for cucumber plantings, 1978-80.

\begin{tabular}{|c|c|c|c|c|}
\hline \multirow{3}{*}{$\begin{array}{c}\text { Tissue } \\
\text { treatment }\end{array}$} & \multicolumn{4}{|c|}{ Rate (g or no./crock) } \\
\hline & \multicolumn{4}{|c|}{ Planting number } \\
\hline & $1-2$ & 3 & 4 & $5-8$ \\
\hline Check & 0 & 0 & 0 & 0 \\
\hline Decaying tubers ${ }^{z}(g)$ & $\begin{array}{l}14 \\
28\end{array}$ & $\begin{array}{l}14 \\
28\end{array}$ & $\begin{array}{l}14 \\
28\end{array}$ & 28 \\
\hline Decaying leaves $^{z}(\mathrm{~g})$ & $\begin{array}{r}10.5 \\
21\end{array}$ & $\begin{array}{r}10.5 \\
21 \\
28 \\
56\end{array}$ & $\begin{array}{r}10.5 \\
28 \\
56\end{array}$ & 28 \\
\hline Sprouting tubers ${ }^{\mathrm{y}}$ (no.) & 40 & 40 & -- & - \\
\hline Growing plants (no.) & $\begin{array}{l}25 \\
50\end{array}$ & $\begin{array}{l}25 \\
50\end{array}$ & $\begin{array}{l}25 \\
50\end{array}$ & 50 \\
\hline
\end{tabular}

${ }^{\mathrm{z}}$ Decaying tubers and leaves were coarsely chopped and incorporated into the top $5 \mathrm{~cm}$ of the medium before planting.

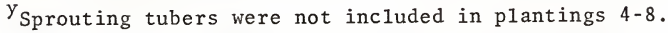


Table 2. C. rotundus material applied to upper crock seed medium for lettuce and tomato plantings, 1979-1980.

Tissue treatment Rate/crock

Check

0

Decaying tubers ${ }^{2}(\mathrm{~g}) \quad 28$

Decaying leaves ${ }^{z}(g) \quad 28$

Growing plants (no.) 50

${ }^{z}$ Decaying tubers and leaves were coarsely chopped and incorporated into the top 5 $\mathrm{cm}$ of the medium before planting. 
Table 3. Planting and harvest dates and seeding rates for bioassay crops in greenhouse experiments, 1978-1980.

\begin{tabular}{lccrr}
\hline Crop & $\begin{array}{c}\text { Planting } \\
\text { no. }\end{array}$ & $\begin{array}{c}\text { No. of seed } \\
\text { planted }\end{array}$ & $\begin{array}{c}\text { Date } \\
\text { planted }\end{array}$ & $\begin{array}{c}\text { Date } \\
\text { harvested }\end{array}$ \\
\hline Cucumber & 1 & 20 & $5-19-78$ & $6-25-78$ \\
& 2 & 10 & $5-30-78$ & $6-29-78$ \\
& 3 & 10 & $6-30-78$ & $8-01-78$ \\
& 4 & 10 & $9-19-78$ & $12-04-78$ \\
& 5 & 10 & $1-11-79$ & $3-26-79$ \\
& 6 & 10 & $9-13-79$ & $10-23-79$ \\
& 7 & 10 & $10-29-79$ & $12-10-79$ \\
Lettuce & 8 & 10 & $1-18-80$ & $3-07-80$ \\
& 1 & 20 & $1-28-79$ & $4-03-79$ \\
Tomato & 2 & 20 & $4-05-79$ & $5-16-79$ \\
& 1 & 25 & $4-09-79$ & $5-07-79$ \\
& 2 & 25 & $5-10-79$ & $6-11-79$ \\
\hline
\end{tabular}




\section{Field Studies: Experiments II and III}

Experiment II was conducted to evaluate the effect of a solid stand of nutsedge on the no. of plants of each weed sp. present in $929 \mathrm{~cm}^{2}$ areas. Counts were made every $1.37 \mathrm{~m}$ in a field infested with $\underline{\text { C. }}$ rotundus located in block 6 of the Horticultural Research Unit and beginning at the S.W. corner of the field. The soil was a Wauchula f.s. (Aeric Haplaquod). The field had been disced on March 4, 1979, and the weed counts were made April 19-21, 1979. The data were subjected to correlation analysis to determine whether there was any correlation between densities of $\underline{\mathrm{C}}$. $\underline{\text { rotundus }}$ and weed sp. observed.

Experiment III was conducted to evaluate tubers and $\mathrm{CH}_{3} \mathrm{OH}$ extracts of tubers as phytotoxins under field conditions. Four treatments were replicated within 5 randomized complete blocks with each plot measuring $91.4 \mathrm{~cm} \times 91.4 \mathrm{~cm}$. The experimental area was prepared by double discing, applying $1210 \mathrm{~kg} / \mathrm{ha}$ of 6-8-8 fertilizer with micronutrients (F.T.E. 503) and rototilling 15 to $20 \mathrm{~cm}$ deep on September 13, 1979. Treatments were as follows: 1) unscreened soil (Wauchula f.s. (Aeric Haplaquod)), 2) soil screened free of tubers and plant debris (123 g/plot), 3) screened soil with the removed $123 \mathrm{~g}$ of tubers chopped in a blender, then incorporated into the top $5-7.6 \mathrm{~cm}$ of the soil by raking, and 4) screened soil with the removed $123 \mathrm{~g}$ of tubers extracted 
with $\mathrm{CH}_{3} \mathrm{OH}$ and the extract sprayed on the soil and incorporated. The $\mathrm{CH}_{3} \mathrm{OH}$ extract was prepared by chopping the tubers in a blender, performing a batch extraction of $614 \mathrm{~g}$ of tubers with 4 liters of $\mathrm{CH}_{3} \mathrm{OH}$ and filtering through Whatman No. 3 filter paper in a Buchner funnel provided with suction. Each sprayed plot received $800 \mathrm{ml}$ of extract with a compressed air herbicide sprayer operated at $2.8 \mathrm{~kg} / \mathrm{cm}^{2}$ and incorporated by raking. The tuber and extract treatments were applied September 23, 1979. On September 24, 1979, a11 plots were raked smooth to remove any sma11 weed seedlings, then seeded to the following crops in rows $12.7 \mathrm{~cm}$ apart: 1) 50 seed of 'Poinsett' cucumber (Cucumis sativus L.), 2) 100 seed of 'Walter' tomato (Lycopersicon esculentum Mi11.), 3) 40 seed of 'Champion' radish (Raphanus sativus L.), and 4) 100 seed of 'Grand Rapids' 1ettuce (Lactuca sativa L.). A fiberglass roof was placed over the plots to reduce leaching losses from September 25, 1979, through October 5, 1979. Irrigation was provided by applying $2.5 \mathrm{~cm}$ of water weekly. Percent emergence and rate of emergence were calculated daily for 8 days. The weeds and crops on the east one-half of each plot $(91.4$ $\mathrm{cm} \times 45.7 \mathrm{~cm}$ ) were harvested October 12-15, 1979, with number of individuals per species and weight recorded. This one-half of the plots was then replanted with the same crops and seeding rates. An early freeze killed this planting before harvest data could be collected. The west one-half of each plot was harvested November 26-28, 1979, recording the same data as for the east one-half. 
Data were subjected to analysis of variance and means between treatments compared with Duncan's new multiple-range test.

\section{Laboratory Studies}

Bioassays--Experiments IV and V

Experiment IV was a series of seed germination bioassays of $\mathrm{CH}_{3} \mathrm{OH}$ extracts of $\underline{\mathrm{C}}$. rotundus tubers and leaves to determine if any allelopathic compounds were present in these tissues. Each bioassay was set up as a completely random design with 4 replications. The first bioassay was begun July 22 , 1978, using freshly collected tissues with treatments as follows: 1) extract of $28 \mathrm{~g}$ (per replicate) fresh leaves, 2) extract of $28 \mathrm{~g}$ (per replicate) fresh tubers, 3) $\mathrm{CH}_{3} \mathrm{OH}$ check, and 4) check without $\mathrm{CH}_{3} \mathrm{OH}$. Batch extracts were prepared by grinding $28 \mathrm{~g}$ of tissue in $100 \mathrm{ml}$ of $\operatorname{cold~} \mathrm{CH}_{3} \mathrm{OH}$ in a commercial Waring blender and allowing the extract to stand for 1 hour. The extract was then vacuum filtered through whatman No. 1 filter paper in a Buchner funnel, and the filtrate was flash evaporated at $37^{\circ} \mathrm{C}$ under vacuum to a final volume of $50 \mathrm{~m} 1$. Ten milliliters of this concentrate was applied to a $9 \mathrm{~cm}$ disc of Whatman No. 3 filter paper in a $9 \mathrm{~cm}$ petri dish and evaporated to dryness in a vacuum desiccator. The $\mathrm{CH}_{3} \mathrm{OH}$ check consisted of filter paper to which $10 \mathrm{ml}$ of $\mathrm{CH}_{3} \mathrm{OH}$ was added, then dried in a vacuum desiccator. The check without $\mathrm{CH}_{3} \mathrm{OH}$ was dry filter paper. Ten 'Poinsett' cucumber seed were placed in each dish with $4 \mathrm{ml}$ distilled water for imbibition and incubated at $25^{\circ} \mathrm{C} \pm 2^{\circ} \mathrm{C}$ for 9 days. Germination 
counts were made daily with germination being defined as follows: 1) emergence of radicle greater than $3 \mathrm{~mm}$, and 2) complete emergence of both radicle and plumule. The average number of days required to germinate (germination rate) was calculated using the equation described in Experiment I.

The second bioassay was conducted for 10 days (August $8-17,1978$ ) using freeze-dried tubers collected in February, 1977. The treatments were as follows: 1) $0.25 \mathrm{~g}$ tubers, 2) $0.50 \mathrm{~g}$ tubers, 3) $2.5 \mathrm{~g}$ tubers, 4) $\mathrm{CH}_{3} \mathrm{OH}$ check, and 5) check without $\mathrm{CH}_{3} \mathrm{OH}$. The extraction procedure was as described for the first bioassay except $25 \mathrm{ml}$ of $\mathrm{CH}_{3} \mathrm{OH}$ was used per replicate. The extract was filtered and reduced to $5 \mathrm{~m} 1$ by flash evaporation at $38^{\circ} \mathrm{C}$. The rest of the procedure was the same as that used in the first bioassay. Each petri dish was seeded with 10 'Poinsett' cucumber seeds and incubated at $25^{\circ} \mathrm{C} \pm 2^{\circ} \mathrm{C}$. Data collected included daily germination counts, germination rate and radicle lengths.

The data for both bioassays were subjected to analysis of variance with treatment means ranked by Duncan's new multiple-range test.

Since $\mathrm{CH}_{3} \mathrm{OH}$ extracts of tubers reduced germination and growth of cucumber, a seed germination bioassay study (Experiment V) was conducted on $\mathrm{CH}_{3} \mathrm{OH}$ extracts of soil and leachates of sand and soil in which nutsedge had grown. The bioassay was of 1) a $\mathrm{CH}_{3} \mathrm{OH}$ control, 2 and 3) $\mathrm{CH}_{3} \mathrm{OH}$ leachates of screened sand or soil, respectively, (Wauchula f.s. (Aeric 
Haplaquod) with $1.7 \%$ organic matter (o.m.)) in which 40 nutsedge plants had grown, 4) extracts of screened Wauchula f.s. in which nutsedge had previously grown, and 5) extracts of screened Wauchula f.s. in which nutsedge had not previously grown. Leachates were obtained by leaching the medium in each crock (4 crocks per treatment) daily for 4 days with $\mathrm{CH}_{3} \mathrm{OH}$ beginning with 1 iter and reusing that which was recovered each day. The leachates were filtered and flash evaporated to $24 \mathrm{ml}$. Four milliliter aliquots were added to petri dishes and dried under vacuum. Soil extracts were prepared by shaking $150 \mathrm{~g}$ of soil in $150 \mathrm{ml} \mathrm{CH} 3$ OH for 6 hours. The extract was then filtered and flash evaporated to a final volume of $15 \mathrm{ml}$. Ten milliliter aliquots were added to petri dishes and dried under vacuum. Twenty-five seeds of either 'Walter' tomato or 'Grand Rapids' lettuce were added to each dish along with $4 \mathrm{ml}$ distilled water. The experimental design was a randomized complete block with 4 replications. Seed were incubated at $24^{\circ} \mathrm{C} \pm 2^{\circ} \mathrm{C}$ starting on March 28, 1979, for 8 days (lettuce) or 11 days (tomato). Data collected were percent germination, germination rate, radicle length and seedling fresh weight. Data were subjected to analysis of variance and treatment means ranked by Duncan's new multiple-range test.

Heat Stability--Experiment VI

The heat stability of tuber extract was determined by placing $1 \mathrm{ml}$ of alcohol-free extract of $\underline{\mathrm{C}}$. rotundus tubers 
in an oven maintained at $60^{\circ} \mathrm{C}$ for 1 hour. The extract was obtained as described in Experiment IV, and the $\mathrm{CH}_{3} \mathrm{OH}$ was removed by flash evaporation at $37^{\circ} \mathrm{C}$. The extract was resolubilized in $10 \mathrm{~m} 1 \mathrm{CH}_{3} \mathrm{OH}$. Two milliliter aliquots were applied to Whatman No. 3. paper discs in four $9 \mathrm{~cm}$ petri dishes and dried in a vacuum desiccator. Additional treatments consisited of an unheated extract of the same concentration and a control. Each petri dish received $4 \mathrm{~m} 1$ distilled water and 10 'Poinsett' cucumber seeds on Apri1 21, 1980. Seed were germinated for 7 days at $28^{\circ} \mathrm{C} \pm 2^{\circ} \mathrm{C}$ with dishes (rep1icates) arranged in a completely random design. Data for percent germination, ADG (germination rate) and root length were subjected to analysis of variance and the treatment means ranked by Duncan's new multiple-range test.

Water Solubility--Experiment VII

Experiment VII was a water solubility study using $1 \mathrm{ml}$ of alcohol-free conc. extract of $\underline{\mathrm{C}}$. rotundus tubers, prepared as described in Experiment VI. Twenty milliliters water were added to the $1 \mathrm{ml}$ of extract, then the solution was agitated, allowed to stand for 24 hours, thoroughly agitated again, filtered through whatman No. 3 filter paper, and $5 \mathrm{ml}$ aliquots added to each of 4 petri dishes fitted with No. 3 Whatman filter paper discs. A check treatment was included. The discs were dried in a vacuum desiccator. Four milliliters distilled water were added, and each dish seeded with 10 'Poinsett' cucumber seed on March 13, 1980. Seed were germinated for 7 
days at $27^{\circ} \mathrm{C} \pm 2^{\circ} \mathrm{C}$ with dishes arranged in a completely random design. Data for percent germination, germination rate and radicle lengths were subjected to analysis of variance and the treatment means ranked by Duncan's new multiple-range test.

Gel Chromatography--Experiment VIII

Tuber extracts, obtained as described in Experiment IV, were gel chromatographed to determine the approximate molecular weight (m.w.) of the unknown growth inhibitor. Sephadex LH-20 gel was solvated with absolute $\mathrm{CH}_{3} \mathrm{OH}$ and placed in an $11 \mathrm{~mm} \times 90 \mathrm{~cm}$ Pharmacia glass column with a volume of $137 \mathrm{~m} 1$. A number of preliminary chromatographs were performed. In these preliminary experiments, maximum inhibitory activity was found in the 96 to $125 \mathrm{ml}$ portions of the elution volume, varying somewhat with flow rate. In all chromatographs, $\mathrm{CH}_{3} \mathrm{OH}$ was the solvent and eluant. The gel column was set up with a $\mathrm{CH}_{3} \mathrm{OH}$ reservoir attached so as to provide a flow rate of $0.060 \mathrm{~m} 1 / \mathrm{min}$. A solution of standards was prepared by combining $5 \mathrm{ml}$ aliquots of solutions of varying concentrations of polyethylene glycol (PEG) 6000, PEG 1000 , PEG 400 and $\mathrm{CaCl}_{2}$ (m.w.= 110.99 amu (atomic mass units)). Peg 6000 was used because it is well beyond the molecular exclusion limit of the $\mathrm{LH}-20 \mathrm{gel}$ in $\mathrm{CH}_{3} \mathrm{OH}(4000 \mathrm{amu})$ and should elute in the void volume $\left(V_{0}\right)$ of the column. The remaining compounds provide 3 additional molecular weight points. One $\mathrm{m} 1$ of the prepared extract or $1 \mathrm{~m} 1$ of the previously mentioned solution of standards of known molecular 
weight was introduced to the top of the column and a Bio-Rad Laboratories automatic fraction collector was attached to the outlet tube. The eluant was collected as $2.4 \mathrm{ml} \mathrm{frac}-$ tions until 135 fractions had been collected. If the introduced sample was tuber extract, a bioassay was conducted by pouring each fraction into a petri dish, drying under vacuum, adding $4 \mathrm{ml}$ distilled water and 10 'Poinsett' cucumber seeds and germinating for 7 days at $27^{\circ} \mathrm{C} \pm 2^{\circ} \mathrm{C}$. Datum collected was radicle length. If the sample was a solution of standards, the refractive index of each fraction was determined, using a Bausch and Lomb refractometer. Graphs were constructed of elution volume $\left(V_{e}\right)$ vs. log molecular weight with elution peaks determined by refractive index (R.I.) and $V_{e} v s$. percent inhibition of cucumber root growth (relative to control), using average values obtained in 2 chromatographic separations. These graphs were used to approximate the molecular weight of the unknown.

Mass Spectrometric Analysis--Experiment IX

A fresh sample of $\underline{\text { C. }}$ rotundus tuber extract was obtained as described in Experiment IV and was chromatographed on the gel column. The 3 consecutive fractions which had shown the most inhibitory activity were analyzed by mass spectrometry in order to determine the identity of the unknown inhibitor. These fractions were combined, reduced in volume to $2 \mathrm{ml}$ by vacuum desiccation, and methylated with diazomethane. The methylated sample was chromatographed on a gas liquid 
chromatograph to further separate the inhibitor from additional compounds. The sample was then passed through a mass spectrometer, and the results analyzed.

Mass spectrometric analysis suggested 2 possible compounds in the inhibitory fraction: protocatechuic acid (3, 4-dihydroxy benzoic acid) and linoleic acid. Therefore, a cucumber seed bioassay with 4 replicates arranged in a completely random design was conducted using the following concentrations and combinations of compounds: 100,500, 1000 and $5000 \mathrm{ppm}$ of a) protocatechuic acid, b) linoleic acid, and c) linoleic and protocatechuic acids. Ten 'Poinsett' cucumber seeds imbibed with $4 \mathrm{ml}$ of water were germinated at $27^{\circ} \mathrm{C} \pm 2^{\circ} \mathrm{C}$ for 7 days. Germination counts were recorded daily. Data subjected to analys is of variance with treatment means ranked by Duncan's new multiple-range test included percent germination, germination rate and root length.

\section{High Pressure Liquid Chromatography--Experiment $\mathrm{X}$}

Experiment $X$ was conducted to improve chemical separation of the allelopaths from associated compounds. An extract of $20 \mathrm{~g}$ of fresh $\underline{\mathrm{C}}$. rotundus tubers in $100 \mathrm{ml} \mathrm{CH} 3 \mathrm{OH}$ was prepared and filtered in the usual manner. The $\mathrm{CH}_{3} \mathrm{OH}$ was removed by flash evaporation at $37^{\circ} \mathrm{C}$ until a dry residue remained. This residue was resolubilized with $2 \mathrm{ml}$ methylene chloride $\left(\mathrm{CH}_{2} \mathrm{Cl}_{2}\right)$. One milliliter of the resulting extract was loaded (by using a glass syringe) onto a silica 
cartridge (Sep-pak (Waters Associates, Framington, Mass.)) prewashed with $5 \mathrm{ml} \mathrm{CH} \mathrm{Cl}_{2}$. A series of $5 \mathrm{ml}$ aliquots of organic solvent mixtures were used to remove contaminating compounds from the silica cartridge (Sep-pak) by washing. A flow rate of approximately $5 \mathrm{ml} / \mathrm{min}$ of aliquot was used throughout. Five aliquots of $\mathrm{CH}_{2} \mathrm{Cl}_{2}$ were followed sequentially by $5 \%(\mathrm{v} / \mathrm{v})$ ether in $\mathrm{CH}_{2} \mathrm{Cl}_{2}, 5 \%$ ethyl acetate in $\mathrm{CH}_{2} \mathrm{Cl}_{2}$, $5 \%$ acetone in $\mathrm{CH}_{2} \mathrm{Cl}_{2}, 4 \% \mathrm{CH}_{3} \mathrm{OH}$ in $\mathrm{CH}_{2} \mathrm{Cl}_{2}, 10,20$ and $60 \% \mathrm{CH}_{3} \mathrm{OH}$ in $\mathrm{CH}_{2} \mathrm{Cl}_{2}$ and 2 aliquots of $100 \% \mathrm{CH}_{3} \mathrm{OH}$. Thus, compounds were eluted by a solvent sequence of increasing polarity. The resulting fractions were bioassayed as previously described by collecting them in petri dishes as they eluted. Also included were a control and the complete unfractionated extract. Each dish was seeded with 10 seeds of 'Poinsett' cucumber and root lengths were measured after 6 days. The data were subjected to analysis of variance with the model based on a randomized complete block design with 3 replications ( 3 Sep-paks) and means ranked by Duncan's new multiple-range test.

The above separation procedure was repeated. The 3 replicates for each active fraction were pooled, then evaporated to dryness in a vacuum desiccator, resolubilized in $1 \mathrm{ml} \mathrm{CH} 3 \mathrm{OH}$ and filtered through a $20 \mu$ (pore diameter) Metricel filter disc. Two $200 \mu 1$ samples of each fraction which had shown activity were injected into a high pressure liquid chromatograph (HPLC) fitted with a u Bondapak C18 column. The HPLC, a Waters Associates Mode1 660 solvent 
programmer, was operated in the reverse phase mode with a linear curve. The mobile phase was water and $\mathrm{CH}_{3} \mathrm{OH}$ which eluted into a Waters Associates Model 450 variable wavelength detector set at $254 \mathrm{~nm}$ with an attenuation range of 0.02 AUFS. Detector response was recorded with a Waters Associates Data Module. Fractions were collected from the column eluant at 1 min intervals with a Gilson Microfractionator. The HPLC program took 20 minutes to go from initial conditions of $10 \% \mathrm{CH}_{3} \mathrm{OH}$ and $90 \%$ water to final conditions of $90 \% \mathrm{CH}_{3} \mathrm{OH}$ and $10 \%$ water. The resultant fractions were bioassayed for inhibition by seed germination in the manner previously described. Ten 'Poinsett' cucumber seeds were used in each petri dish. Data for radicle lengths were analyzed for significance by analysis of variance. The treatment means were ranked by Duncan's new multiple-range test. 


\section{RESULTS}

\section{Greenhouse Studies: Experiment I}

The stairstep arrangement of crocks employed in the greenhouse studies allows separation of allelopathic effects from those of competition. Growth reductions of cucumber growing in upper crocks receiving the nutsedge tissue treatments reflect the effects of competition and/or allelopathy, while reductions in lower crocks receiving leachates from upper crocks result from allelopathic effects of the treatments. In these studies, allelopathic effects varied with season.

First Cucumber Planting: May 19, 1978

Addition of nutsedge material to the sand of upper crocks significantly influenced emergence percentage, emergence rate and fresh weight of cucumber (Table 4). Cucumber emergence $(\%)$ was higher in upper crocks receiving the various nutsedge treatments than in the control treatment (Table 5). Emergence rate of cucumber plants grown in upper crocks was significantly decreased by the addition of both rates of growing nutsedge plants and the highest rates of decaying tubers and leaves. Fresh weight of cucumber plants grown in upper crocks was significantly reduced by both rates of growing nutsedge plants and sprouting nutsedge tubers. The greatest weight reduction over the control was $4.6 \mathrm{~g}$, produced by the addition of 25 growing nutsedge plants to the 
Tab1e 4. Mean squares for the analyses of variance of the effect of $\mathrm{C}$. rotundus material in upper crock medium on growth of cucumber planted on May 19, 1978, in upper and lower crocks (planting number 1).

\begin{tabular}{|c|c|c|c|c|c|c|c|}
\hline \multirow{3}{*}{$\begin{array}{l}\text { Source of } \\
\text { variation }\end{array}$} & \multirow[b]{3}{*}{$\mathrm{df}$} & \multicolumn{4}{|c|}{ P1ant emergence } & \multirow{2}{*}{\multicolumn{2}{|c|}{$\begin{array}{l}\text { Fresh wt } \\
\text { (g/plant) }\end{array}$}} \\
\hline & & \multicolumn{2}{|c|}{ Tota $1(\%)$} & \multicolumn{2}{|c|}{ Rate (days) } & & \\
\hline & & Upper & Lower & Upper & Lower & Upper & Lower \\
\hline Treatments & 7 & $37.5 \% *$ & 17.4 & $0.32 *$ & 0.17 & $12.3^{*}$ & 3.9 \\
\hline B1ocks & 3 & 27.1 & 26.0 & 0.17 & 0.32 & 8.5 & 13.7 \\
\hline Error & 21 & 11.6 & 36.8 & 0.11 & 0.08 & 4.0 & 3.4 \\
\hline
\end{tabular}




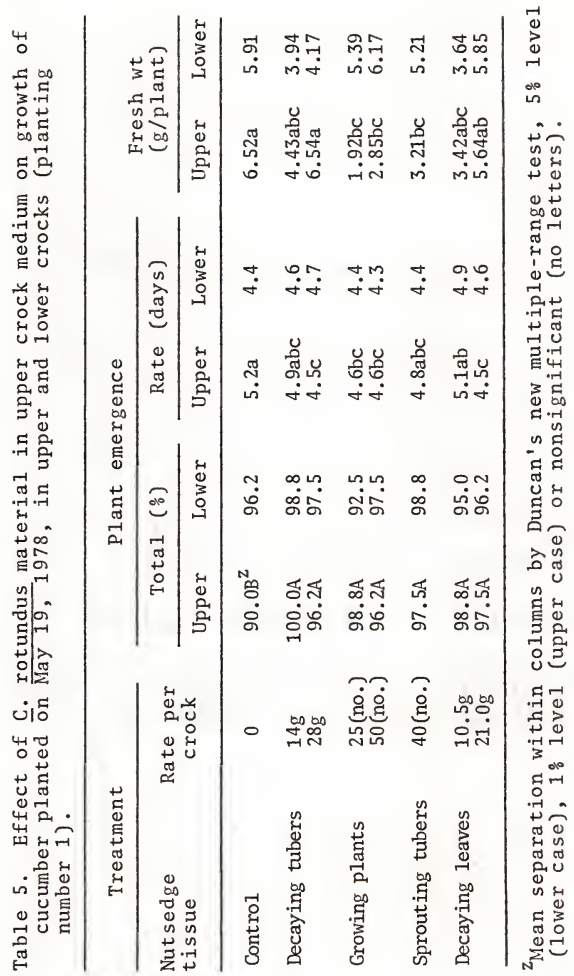


seed medium. Leachates from the various treatments had no effect on percent emergence, emergence rate or fresh weight of cucumber plants grown in lower crocks.

Second Cucumber Planting: May 30, 1978

Emergence of cucumbers in upper and lower crocks of the May 30,1978 , planting was not significantly affected by any treatment (Table 6). Although there were significant changes in diameter and length of cucumber plants grown in upper crocks, there were no significant differences in these parameters for cucumber plants in lower crocks. Diameter of cucumber plants in upper crocks was increased by incorporation of $28 \mathrm{~g}$ of decaying tubers, but was decreased by both rates of growing nutsedge plants and sprouting tubers as compared to the contro1 (Table 7). Cucumber shoot length was decreased where grown with 50 growing nutsedge plants in the seed medium of upper crocks, but increased in the presence of $21 \mathrm{~g}$ of decaying nutsedge leaves. Dry weight of cucumber plants in upper crocks was significantly reduced over the control by the addition of $14 \mathrm{~g}$ decaying nutsedge tubers, both rates of growing nutsedge plants and sprouting tubers to the sand medium. None of the treatments significantly influenced dry weight of cucumber plants grown in lower crocks as compared to the control; however, $10.5 \mathrm{~g}$ decaying leaves did result in weights higher than any of the other nutsedge treatments. 


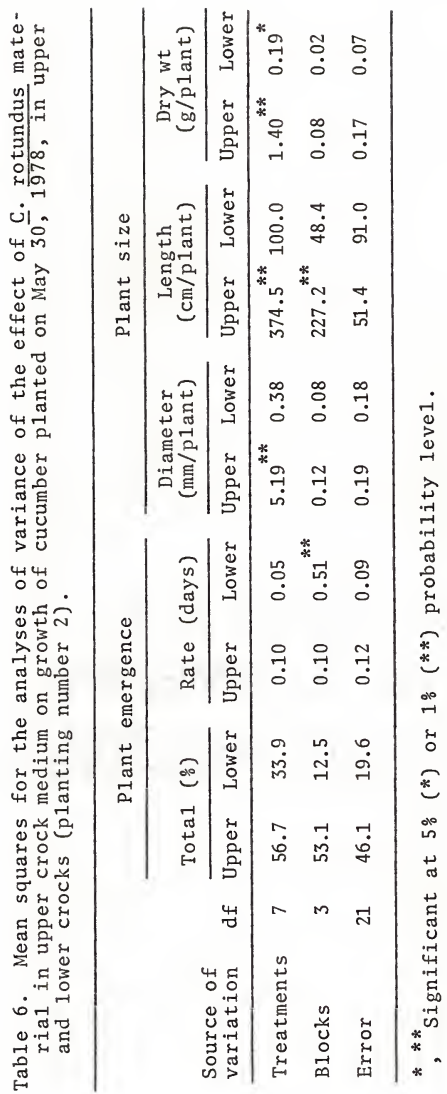




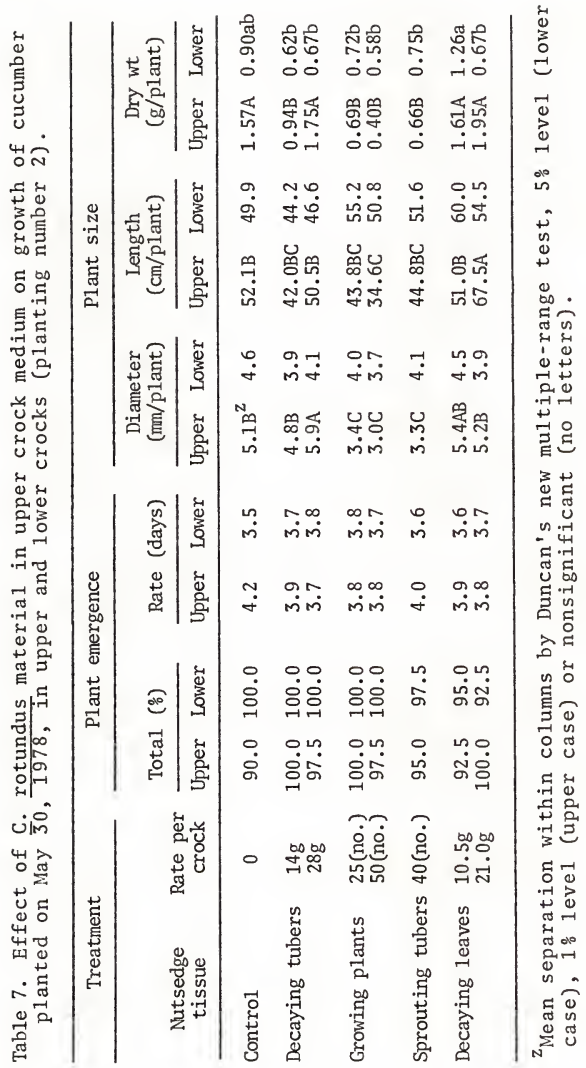


Third Cucumber Planting: June 30, 1978

Cucumber seedling emergence $(\%)$ was not affected by treatment in either upper or lower crocks (Table 8). Emergence rate, diameter, length and dry weight of cucumber plants grown in upper crocks were significantly altered by the treatments, but the same growth parameters for cucumber plants grown in lower crocks were not significantly influenced by the treatments. Emergence rate and diameter of cucumber plants in upper crocks were reduced by the 2 rates of growing nutsedge plants in the medium (Table 9). Where cucumber plants were grown in the presence of growing nutsedge plants (both rates) and 28 and $56 \mathrm{~g}$ of decaying nutsedge leaves, cucumber plant length was reduced by as much as $63 \mathrm{~cm}$ compared to the control. Plant dry weight was also reduced by these 4 treatments and by the addition of sprouting tubers to the seed medium.

Fourth Cucumber P1anting: September 19, 1978

Emergence $(\%)$ of cucumbers planted in upper crocks on September 19, 1978, was significantly influenced by the treatments (Table 10). Emergence $(\%)$ and emergence rate of cucumbers planted in lower crocks and emergence rate of cucumbers planted in upper crocks were not significantly affected by the treatments. Incorporation of $28 \mathrm{~g}$ of decaying nutsedge tubers into the sand of upper crocks significantly reduced emergence $(\%)$ of cucumber plants growing in them (Table 11). The remaining treatments did not significantly affect percent 


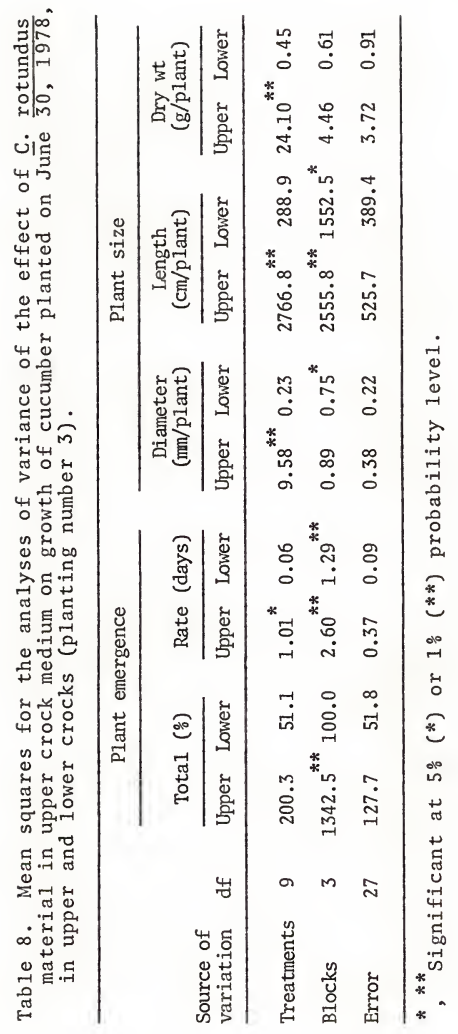




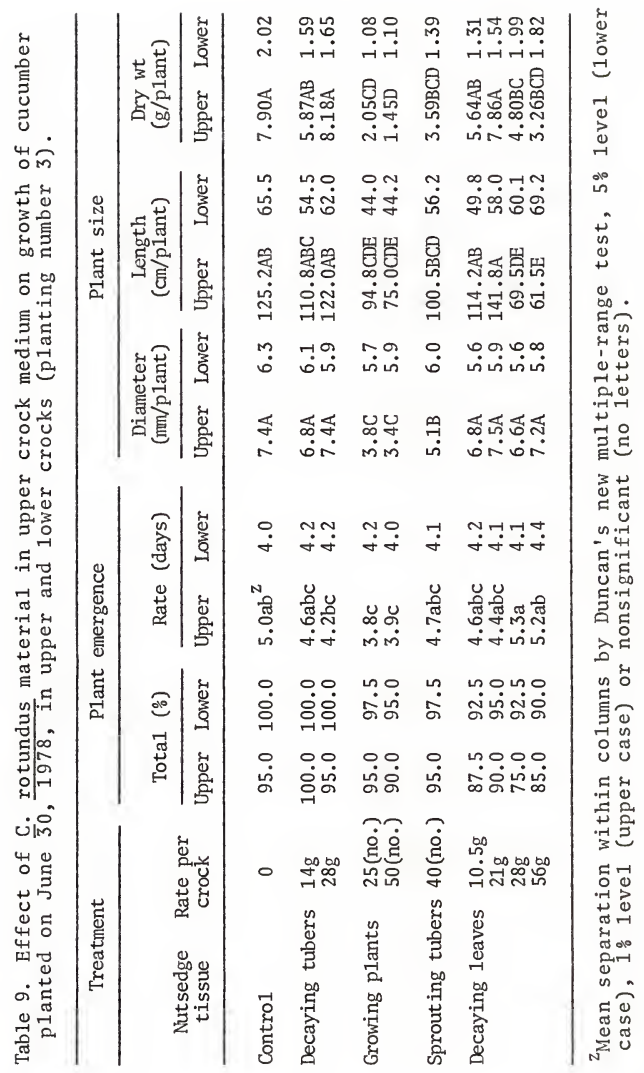




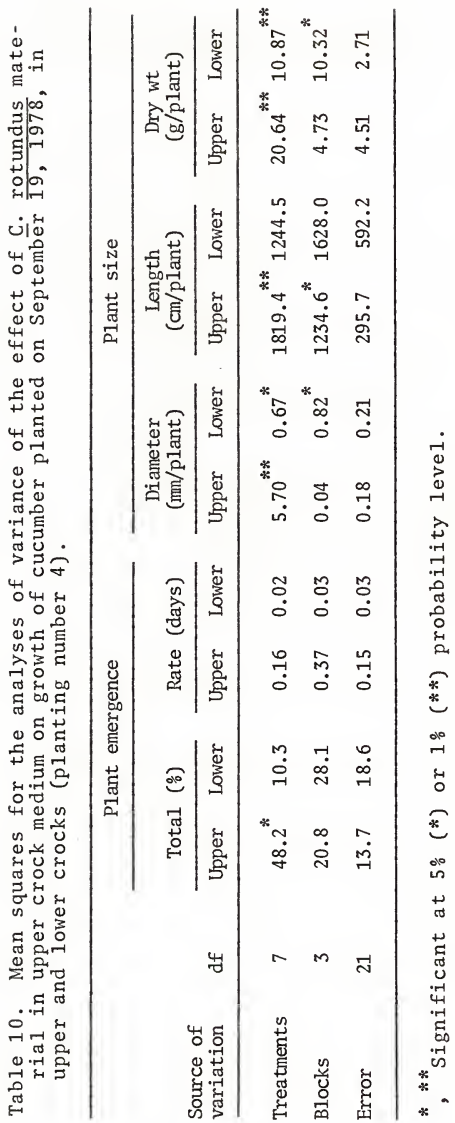




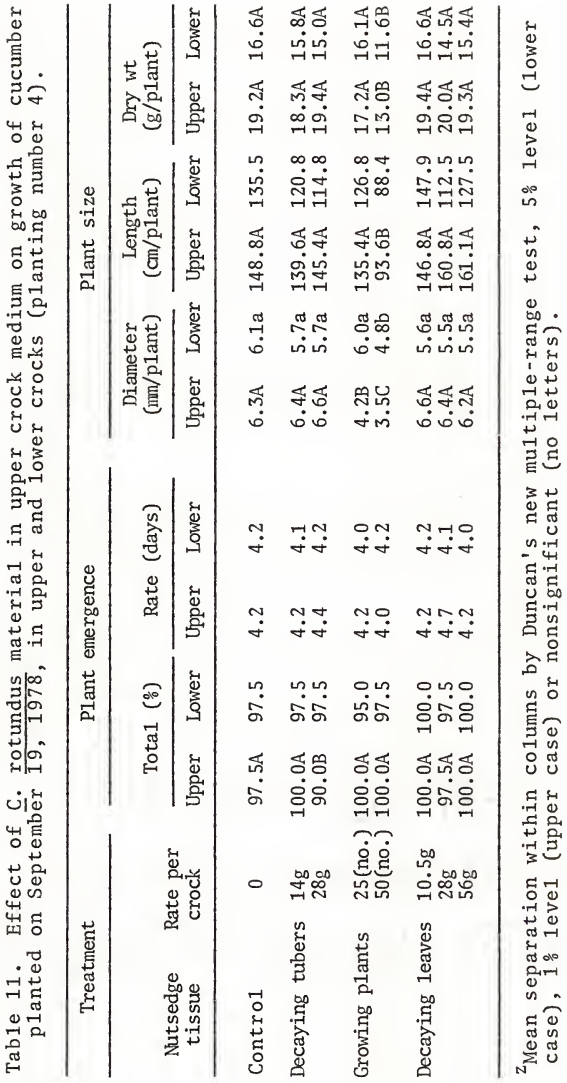


emergence of cucumber plants. Diameter and dry weight of cucumber plants grown in upper and lower crocks were significantly influenced by treatments. Length of cucumber plants grown in upper crocks was significantly affected by treatments, but length of plants in lower crocks was not. Diameter of cucumber plants grown in upper crocks was reduced by both rates of growing plants, while diameter of plants in lower crocks was reduced only by the high rate of nutsedge plants. Leachates from upper crocks containing 50 growing nutsedge plants reduced dry weight of cucumber plants grown in lower crocks. Length of cucumber plants grown in upper crocks was reduced by $55 \mathrm{~cm}$ over the control where 50 nutsedge plants were growing in the same crocks. Although length of cucumber plants grown in lower crocks was not significantly different, plants which received leachate from 50 nutsedge plants tended to be smaller.

Fifth Cucumber Planting: January 11, 1979

No significant differences were found for emergence percentage and rate and dry weight of cucumber plants grown in either upper or lower crocks (Table 12). The addition of 50 growing nutsedge plants to the seed medium of upper crocks significantly reduced diameter and length of cucumber plants grown in upper crocks (Table 13). Diameter and length of cucumber plants grown in lower crocks were not significantly influenced by the treatments. 


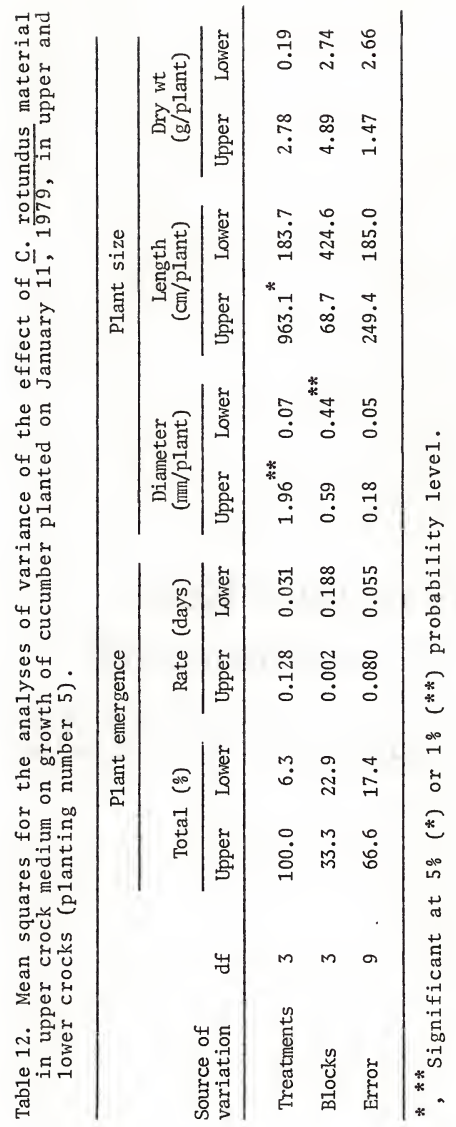




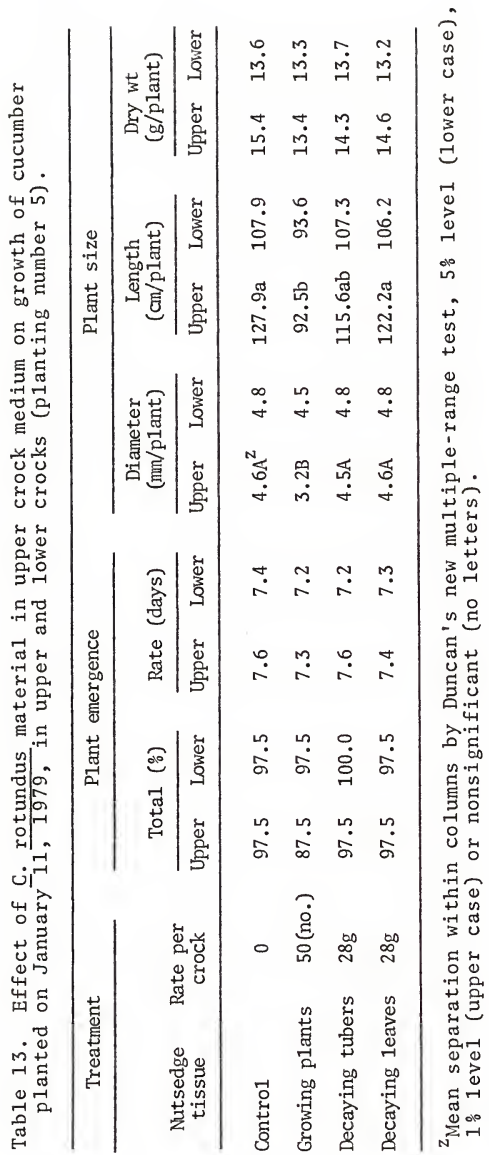


Sixth Cucumber P1anting: September 13, 1979

Diameter, length and fresh and dry weights of cucumber plants grown in upper and lower crocks were significantly influenced by treatment, but treatment had no effect on emergence of cucumber plants grown in upper and lower crocks (Table 14). Fifty nutsedge plants growing in the medium of upper crocks and leachate from these reduced diameter, length and fresh and dry weights of cucumber plants grown in upper and lower crocks (Table 15). Leachates from upper crocks containing decaying nutsedge leaves and tubers significantly reduced fresh and dry weights of cucumber plants grown in lower crocks. Leachates from upper crocks containing decaying nutsedge leaves also reduced length of cucumber plants grown in lower crocks.

Seventh Cucumber P1anting: October 29, 1979

Addition of nutsedge materials to the medium of upper crocks and leachates from these entering the lower crocks significantly influenced diameter, length and fresh and dry weights of cucumber plants planted on October 29, 1979 (Table 16). Cucumber emergence in upper and lower crocks was not influenced by treatment. The presence of growing nutsedge plants in the medium reduced diameter, length and fresh and dry weights of cucumber plants grown in upper crocks (Table 17). Leachates from growing plants and decaying leaves of purple nutsedge significantly reduced length of cucumber plants grown in lower crocks with the 


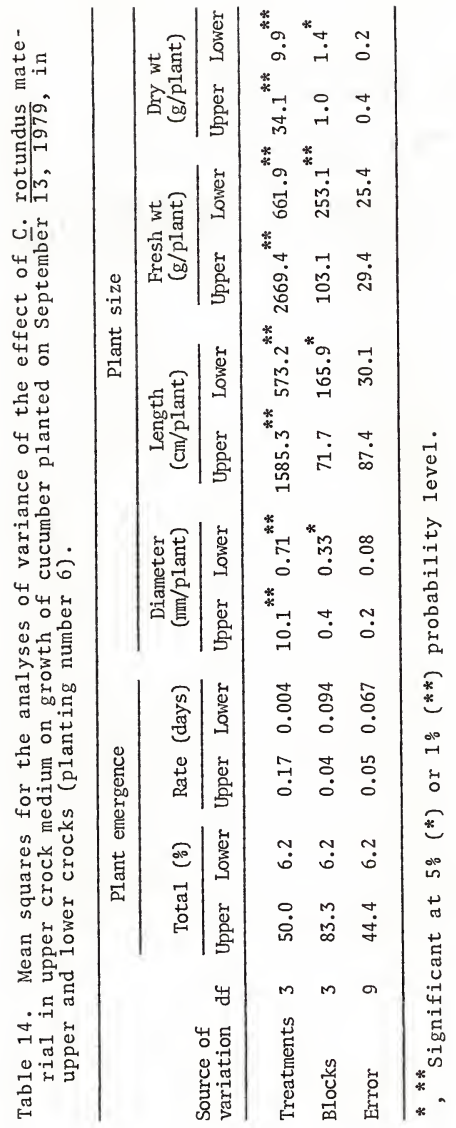




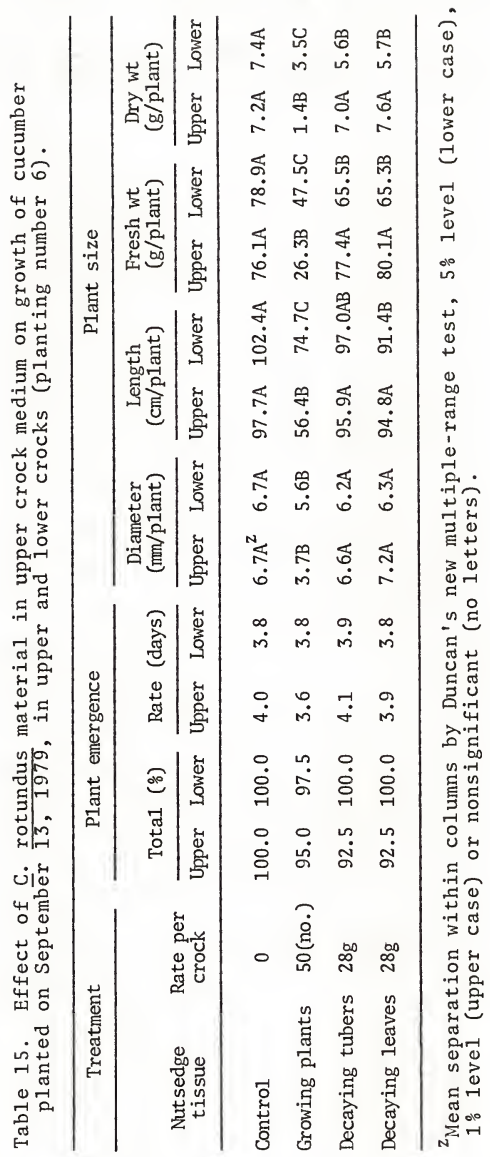




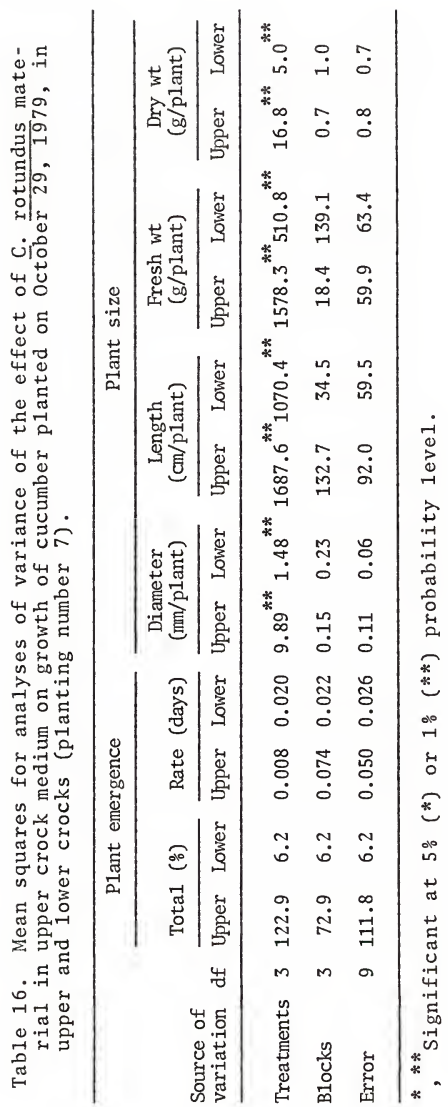




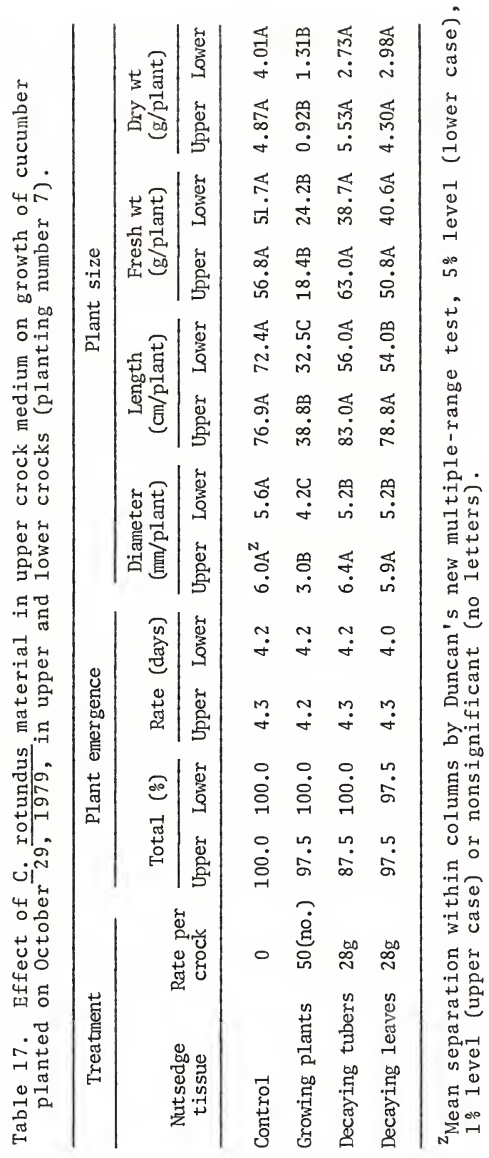


greatest reduction due to the leachate from nutsedge plants. The only treatment to significantly reduce fresh and dry weights of cucumber plants grown in lower crocks was the leachate from growing nutsedge plants; however, there was a trend for reduction in fresh and dry weights where receiving leachates from decaying leaves and tubers.

Eighth Cucumber Planting: January 18, 1980

Treatment effects in the eighth planting were similar to those in the sixth planting. Emergence of cucumbers planted on January 18, 1980, in upper and lower crocks was not significantly influenced by any of the nutsedge treatments (Table 18). Plant diameter, length and fresh and dry weights of cucumbers planted in both upper and lower crocks were significantly influenced by the treatments. The presence of growing nutsedge plants in the seed medium of upper crocks reduced cucumber plant diameter, length and fresh and dry weights (Table 19). Leachates from growing nutsedge plants and decaying tubers reduced diameter, length and fresh and dry weights of cucumber plants growing in lower crocks, while leachates from decaying nutsedge leaves only reduced fresh and dry weights of cucumber plants.

First Lettuce Planting: January 28, 1979

Since leachates from the various nutsedge tissues did not reduce cucumber growth in lower crocks in spring or 


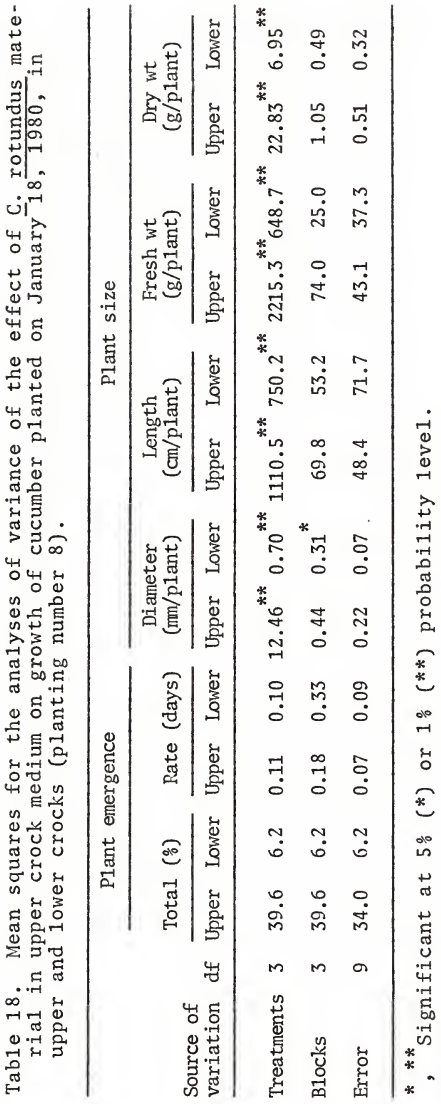




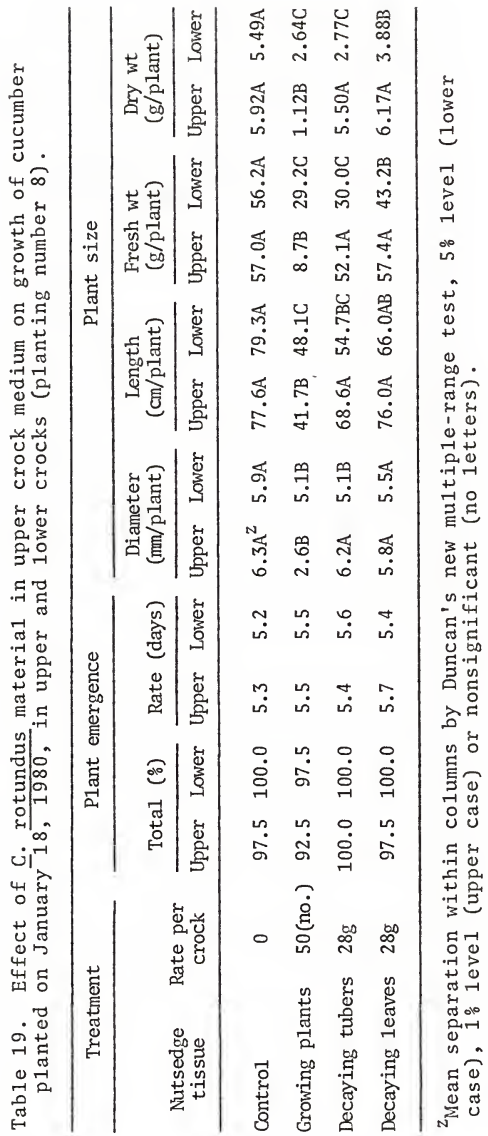


summer, lettuce and tomato were tried as bioassay or indicator plants.

Addition of nutsedge materials to the growing medium significantly influenced percent emergence of lettuce seeded in upper crocks on January 28,1979 , but had no significant effect on either emergence rate in upper and lower crocks or percent emergence in lower crocks (Table 20). Leaf area and fresh weight of lettuce grown in upper and lower crocks were influenced by the treatments. Nutsedge plants growing in the seed medium of upper crocks reduced percent emergence of lettuce seedlings by nearly $40 \%$ over the control, but neither decaying tubers not leaves significantly affected percent emergence of lettuce (Table 21). All nutsedge treatments reduced leaf area and fresh weight of lettuce grown in upper crocks compared to the control, with the greatest effect produced by growing nutsedge plants in the seed medium of upper crocks. Leachate from growing nutsedge plants significantly reduced leaf area and fresh weight of lettuce grown in lower crocks, but leachates from decaying tubers and leaves of nutsedge did not.

Second Lettuce Planting: April 5, 1979

Emergence percentage of lettuce planted in the spring of 1979 in upper and lower crocks was not significantly affected by the treatments; however, the rate of emergence was (Table 22). Lettuce emerged faster in those upper and lower crocks receiving the growing nutsedge plants treatment, while 


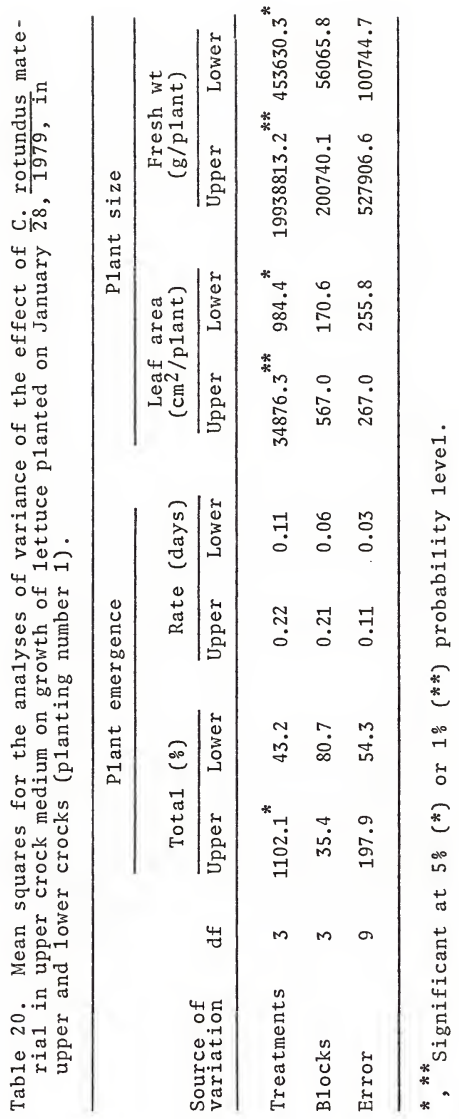




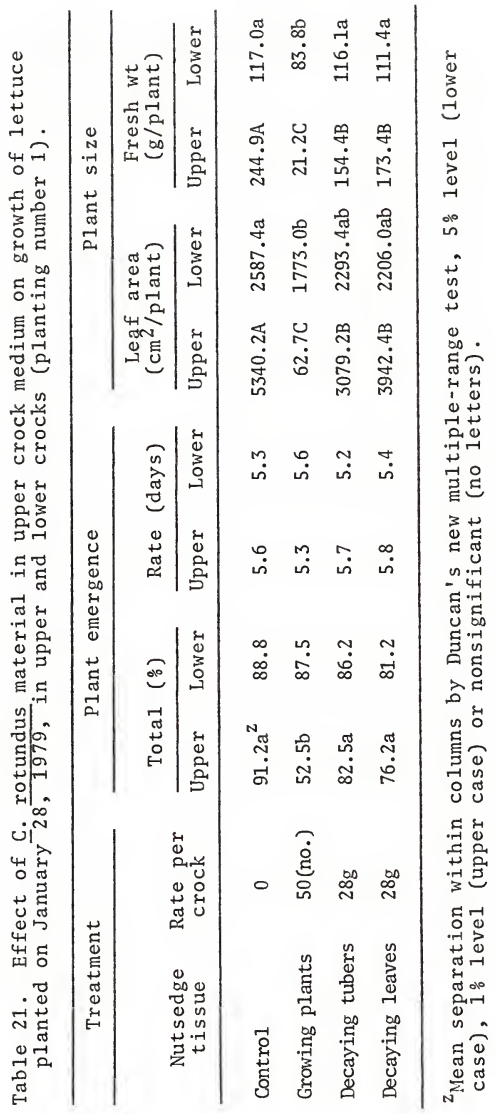




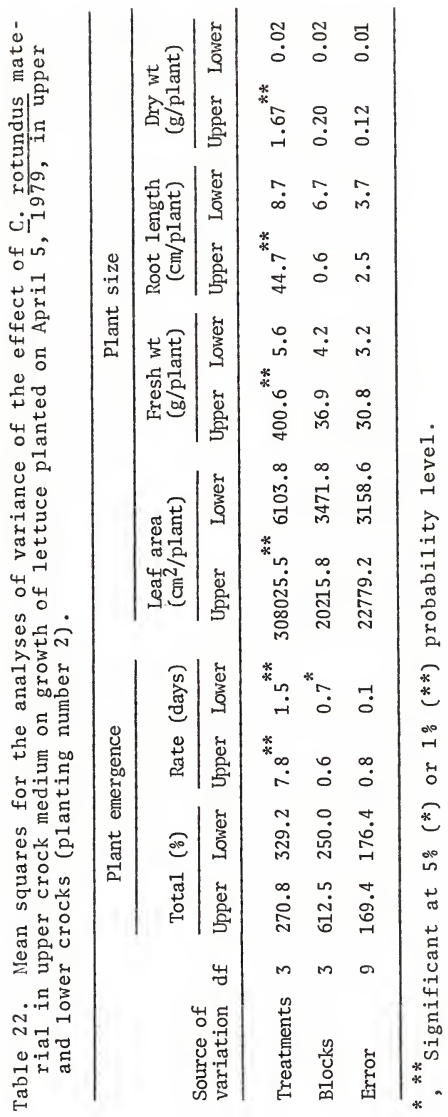


leachate from decaying tubers reduced emergence rate of lettuce grown in lower crocks (Table 23). Although treatment significantly influenced leaf area, primary root length and fresh and dry weights of lettuce grown in upper crocks, these differences were not found in lettuce grown in lower crocks. The presence of growing nutsedge plants and decaying tubers in the seed medium of upper crocks reduced leaf area and fresh and dry weights of lettuce grown in upper crocks. The greatest reductions in leaf area and dry weight of lettuce were due to the growing nutsedge plants treatment. The length of the primary or tap root of lettuce grown in upper crocks was decreased by the presence of decaying leaves and growing plants of nutsedge with the greatest reduction resulting from the growing nutsedge plants treatment.

First Tomato P1anting: Apri1 9, 1979

Emergence and length of tomato plants grown in both upper and lower crocks were not significantly influenced by the various treatments; however, significant differences did occur in plant diameter, root length and fresh weight of tomato plants grown in upper and lower crocks (Table 24). Nutsedge plants growing in the seed medium of upper crocks and leachates from these plants reduced root length and diameter of tomato plants grown in upper and lower crocks below those of the control and decaying tissue treatments (Table 25). Although the presence of nutsedge plants in the seed medium reduced fresh weight of tomato plants grown in 


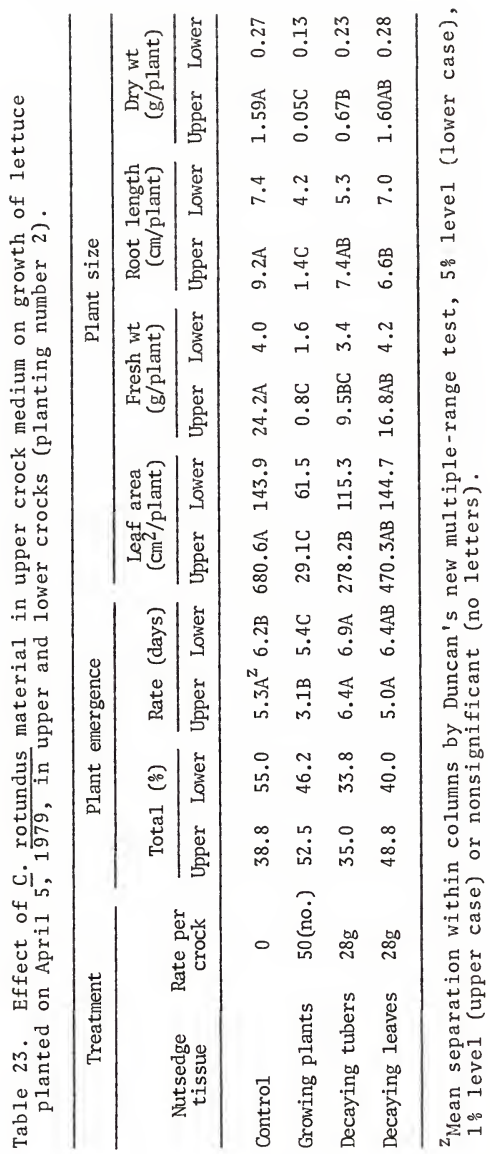




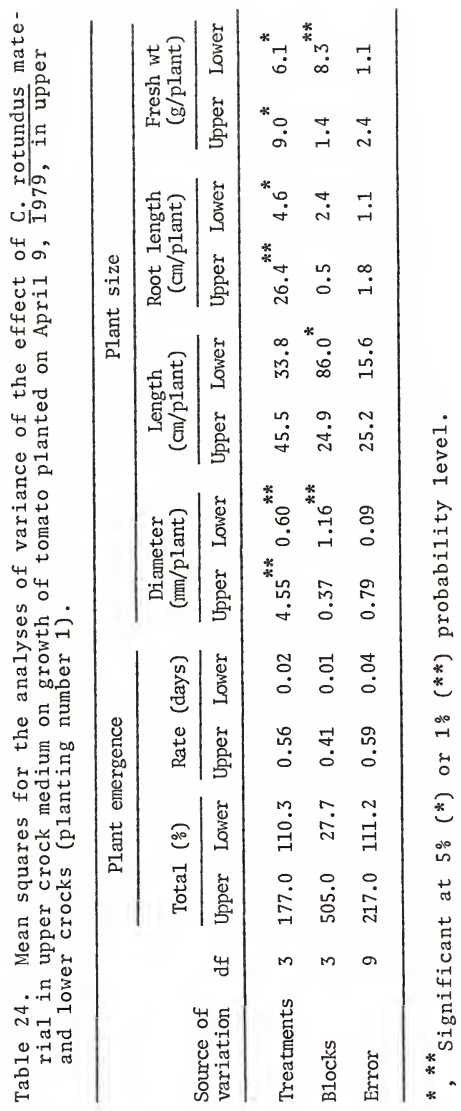




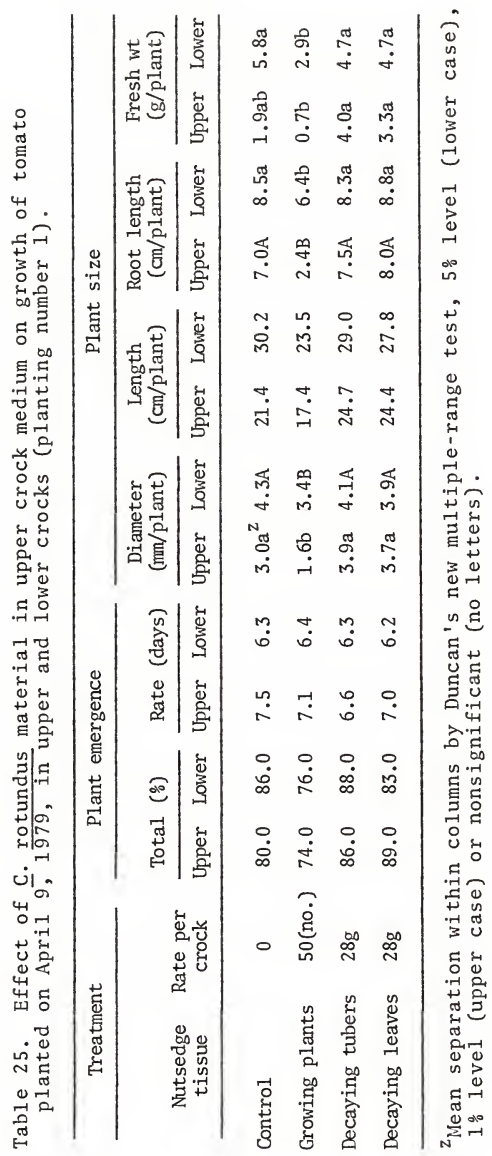


upper crocks relative to the 2 decaying tissue treatments, there were no significant differences between any of the nutsedge treatments and the control. Fresh weight of tomato plants grown in lower crocks which received leachate from growing nutsedge plants was also reduced compared to the other treatments. Plant weight was approximately one-half that of the control.

Second Tomato Planting: May 10, 1979

As in previous spring and summer plantings of cucumber, some growth parameters of tomatoes grown in upper crocks were significantly influenced by treatments, while growth of tomato plants grown in lower crocks was not significantly affected (Table 26). Percent emergence and length of entire plant and shoot of tomatoes grown in upper crocks were not significantly affected by any treatment. Emergence rate of toma to plants grown in upper crocks was increased by decaying tubers and growing plants of nutsedge relative to the control (Table 27). Although the presence of growing nutsedge plants in the seed medium of upper crocks reduced tomato plant diameter over that with the decaying tissue treatments, the differences in plant diameter between the nutsedge treatments and the control were not significant. Growing nutsedge plants in the seed medium of the upper crocks reduced tomato root length to approximately one-third the length of tomato roots in the control. Dry weight of tomato plants in upper crocks that received decaying tubers was over 3 times 


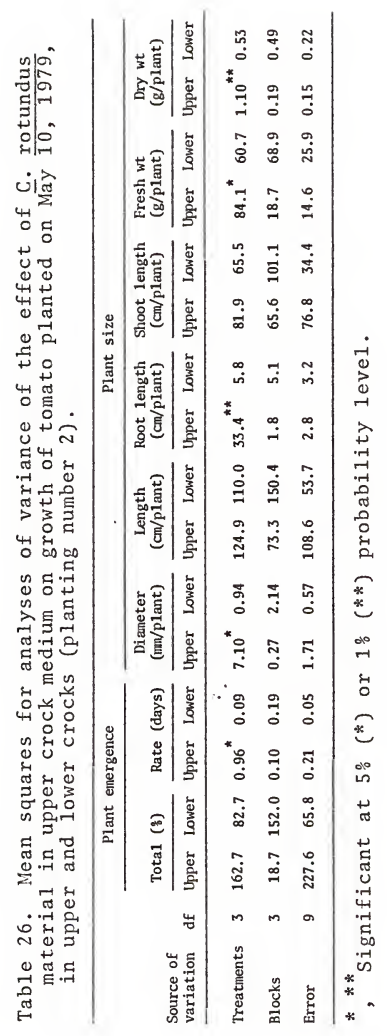




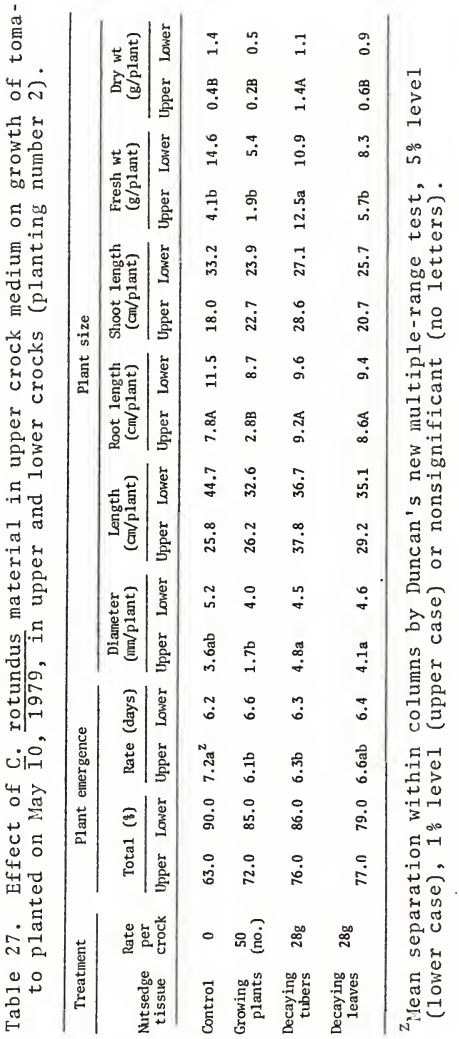


greater than that of the control and growing nutsedge plants treatments and more than twice the weight of tomato plants grown in the presence of decaying leaves. 
Field Studies

Since allelopathic reductions in growth of cucumber, lettuce and tomato were demonstrated in the greenhouse studies, field experiments were conducted to determine if an allelopathic response to natural nutsedge populations and tuber treatments occurred.

Experiment II

Since negative correlations between species are suggestive of allelopathic interactions, the predominant broadleaved and grass species were counted and their population densities (no.) compared by correlation analysis. The major broadleaved weeds were Richardia scabra L., Raphanus raphanistrum L., Oenothera 1aciniata Hill, Euphorbia hirta L., Geranium carolinianum L. and Mollugo verticillata L., while the predominant grasses were Digitaria sanguinalis (L.) Scop. and Eleusine indica (L.) Gaertn. Purple nutsedge was a1most exclusively the only sedge present. Correlation analysis between each weed species and nutsedge indicated that significant correlations occurred between densities of nutsedge and $\underline{R}$. scabra, $\underline{\text { E. hirta }}$ and $\underline{\text { G. carolinianum with }}$ correlation coefficients ( $\mathrm{r}$ values) of $-0.41,0.39$ and 0.29 , respectively (Table 28). Regression analyses were then performed for quadratic and logarithmic models. $\mathrm{R}^{2}$ values for these 3 species based on the quadratic model were $0.18,0.16$ and 0.09 , respectively. The logarithmic model gave $\mathrm{R}^{2}$ values 
Tab1e 28. Correlations between C. rotundus densities and densities of other weed species.

\begin{tabular}{cc}
\hline $\mathrm{Sp}$. & $\underline{\mathrm{C}}$ rotundus density \\
\hline Correlation coefficient, $\mathrm{r}$
\end{tabular}

Digitaria sanguina1is

$-0.28492$

Cynodon dactylon

$-0.23246$

Richardia scabra

$-0.41470 * * 2$

Raphanus raphanistrum

$-0.04357$

Linaria canadensis

$-0.21103$

Cerastium vulgatum

$-0.02444$

Oenothera laciniata

0.08356

Eleusine indica

0.21373

Gnaphalium sp.

0.05207

Euphorbia hirta

0.39287 * *

Lepidium virginicum

0.20198

Geranium carolinianum

0.28689 *

Oxa1is stricta

$-0.12998$

Mollugo verticillata

0.15188

Amaranthus sp.

$-0.08448$

Plantago major

0.00386

Solanum americanum

$-0.09653$

${ }^{z}$ Significant at the $5 \%(*)$ or $1 \%\left({ }^{* *}\right)$ probability leve1. 
of $0.181,0.090$ and 0.049 , respectively. Thus, the linear model did not describe the relationship any better than the other models. The negative correlation between densities of nutsedge and $\underline{\mathrm{R}}$. scabra suggested allelopathic effects of nutsedge may have reduced the density of $\underline{\mathrm{R}}$. $\underline{\mathrm{scabra}}$.

\section{Experiment III}

The effects of incorporation of mascerated tubers and a $\mathrm{CH}_{3} \mathrm{OH}$ extract of nutsedge tubers into a natural field soil were determined in experiment III. Number of plants of cucumber and tomato and percent emergence of tomato were significantly affected by the various treatments, but significant differences were not obtained for the remaining growth parameters of these 2 species or the growth of radish and lettuce plants (Tables 29 and 30 ). Chopped tubers added to the soil reduced the no. of cucumber plants harvested to 2.8 compared to 10.2 in the unscreened control treatment. There were no differences between the screened and unscreened controls or between the screened control and the 2 tuber treatments.

Percent emergence and no. of tomato plants harvested October 15, 1979, were reduced by screening the soil (screened vs. unscreened control) but were not significantly influenced by the tuber treatments. The predominant 7 weed spp. present in these plots were also harvested October 15, 1979. Populations of $\underline{R}$. Scabra and $\underline{R}$. raphanistrum were the only ones significantly altered by treatment (Table 31). 
Table 29. Mean squares for the analyses of variance of the effects of $\underline{C}$. rotundus tubers and tuber extract on number and growth of radish, cucumber, tomato and lettuce plants in field plots, October 15, 1979.

\begin{tabular}{|c|c|c|c|c|c|}
\hline \multirow{2}{*}{$\begin{array}{l}\text { Source of } \\
\text { variation }\end{array}$} & \multirow[b]{2}{*}{$d f$} & \multicolumn{2}{|c|}{ P1ant emergence } & \multirow{2}{*}{$\begin{array}{l}\text { No. per } \\
46 \mathrm{~cm} \text { row }\end{array}$} & \multirow{2}{*}{$\begin{array}{l}\text { P1ant dry wt } \\
\text { (g/p1ant) }\end{array}$} \\
\hline & & Total $(\%)$ & Rate (days) & & \\
\hline \multicolumn{6}{|c|}{ Radish } \\
\hline $\begin{array}{l}\text { Treatments } \\
\text { Blocks } \\
\text { Error }\end{array}$ & $\begin{array}{r}3 \\
4 \\
12\end{array}$ & $\begin{array}{l}431.2 \\
670.6 \\
287.5\end{array}$ & $\begin{array}{l}0.117 \\
0.182 \\
0.150\end{array}$ & $\begin{array}{l}34.33 \\
37.88 \\
13.04\end{array}$ & $\begin{array}{l}0.006 \\
0.006 \\
0.003\end{array}$ \\
\hline \multicolumn{6}{|c|}{ Cucumber } \\
\hline $\begin{array}{l}\text { Treatments } \\
\text { B1ocks } \\
\text { Error }\end{array}$ & $\begin{array}{r}3 \\
4 \\
12\end{array}$ & $\begin{array}{l}961.8 \\
767.3 \\
302.0\end{array}$ & $\begin{array}{l}0.21 \text { * } \\
0.27 \\
0.08\end{array}$ & $\begin{array}{l}47.8^{*} \\
35.8 \\
11.5\end{array}$ & $\begin{array}{l}0.013 \\
0.031 \\
0.032\end{array}$ \\
\hline \multicolumn{6}{|c|}{ Tomato } \\
\hline $\begin{array}{l}\text { Treatments } \\
\text { B1ocks } \\
\text { Error }\end{array}$ & $\begin{array}{r}3 \\
4 \\
12\end{array}$ & $\begin{array}{r}2775.3^{* *} \\
79.9 \\
279.2\end{array}$ & $\begin{array}{l}0.96 \\
0.64 \\
0.42\end{array}$ & $\begin{array}{c}493.4^{*} \\
37.7 \\
104.1\end{array}$ & $\begin{array}{l}0.017 \\
0.003 \\
0.006\end{array}$ \\
\hline \multicolumn{6}{|c|}{ Lettuce } \\
\hline $\begin{array}{l}\text { Treatment } \\
\text { Blocks } \\
\text { Error }\end{array}$ & $\begin{array}{r}3 \\
4 \\
12\end{array}$ & $\begin{array}{r}147.0 \\
101.9 \\
49.5\end{array}$ & $\begin{array}{l}0.04 \\
0.37 \\
0.12\end{array}$ & $\begin{array}{l}27.5 \\
14.9 \\
11.7\end{array}$ & $\begin{array}{l}0.07 \\
0.05 \\
0.04\end{array}$ \\
\hline
\end{tabular}




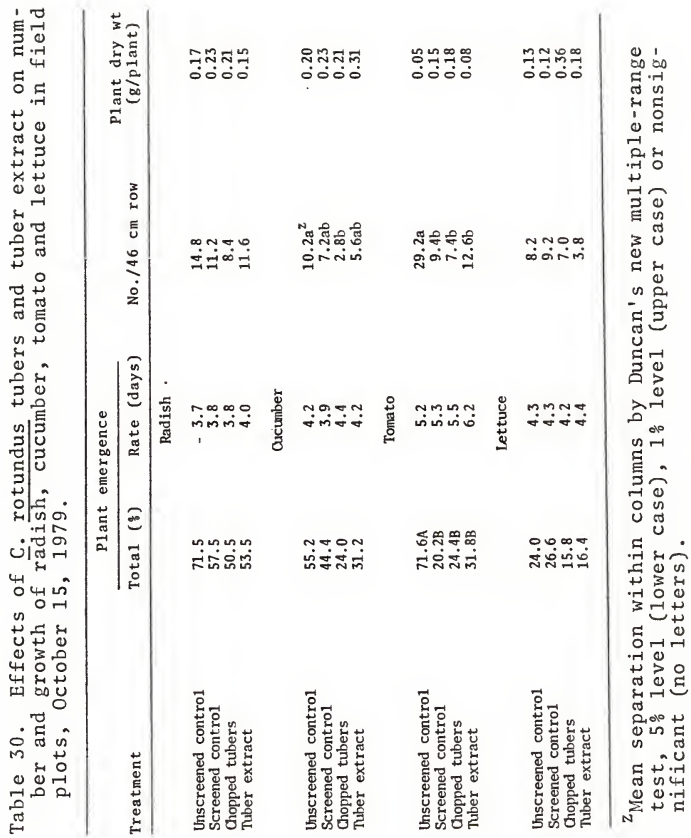




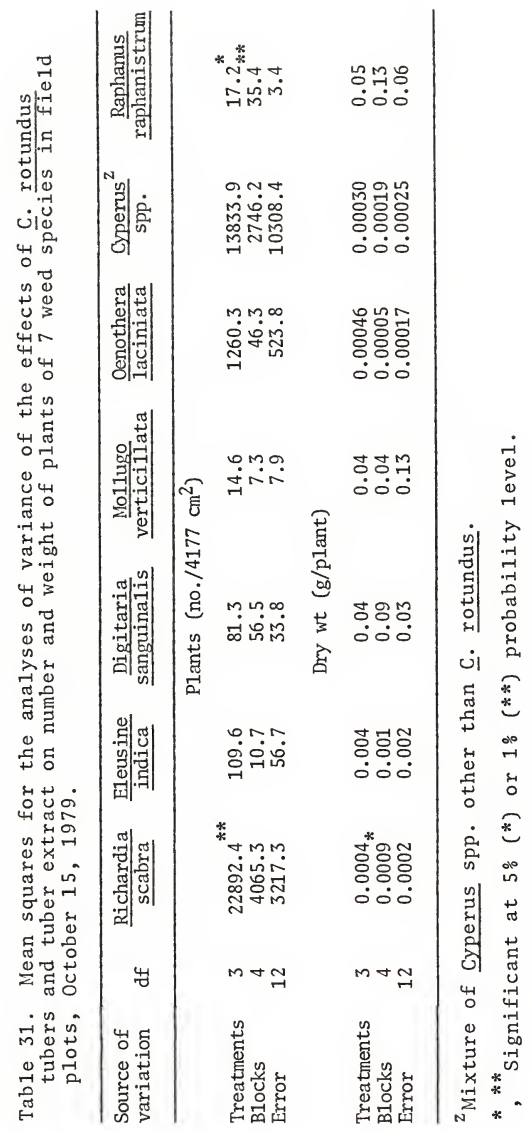


Dry weights of harvested weed spp. were not significantly influenced by treatment. Although screening the soil reduced the no. of $\underline{R}$. scabra and $\underline{R}$. raphanistrum plants, the tuber treatments had no significant effect on population sizes relative to the screened control treatment (Table 32). Treatment significantly influenced the no. of cucumber plants, but not the no. of radish, tomato or lettuce plants, or dry weight of the 4 crops harvested November 28, 1979 (Table 33). The no. of cucumber plants was almost 10 times less in plots sprayed with tuber extract than in plots which received control treatments (Table 34). Incorporation of chopped nutsedge tubers had no significant effect on the no. of cucumber plants.

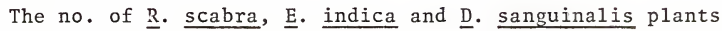
harvested on November 28, 1979, were significantly influenced by the treatments (Table 35). Screening the soil reduced the no. of $\underline{R}$. Scabra plants to one-fourth the no. in the unscreened control, whereas there were no significant differences in no. of $\underline{R}$. scabra plants between the tuber treatments and the screened control (Table 36). The no. of E. indica plants in plots sprayed with tuber extract was significantly lower than in the screened control. Incorporation of chopped tubers in the soil did not significantly affect the no. of $\underline{E}$. indica plants that emerged. Screening the soil significantly increased the no. of $\underline{D}$. sanguinalis plants that emerged over those in the unscreened control. Incorporation of tuber extract in the soil reduced the no. of $\underline{D}$. sanguinalis plants 


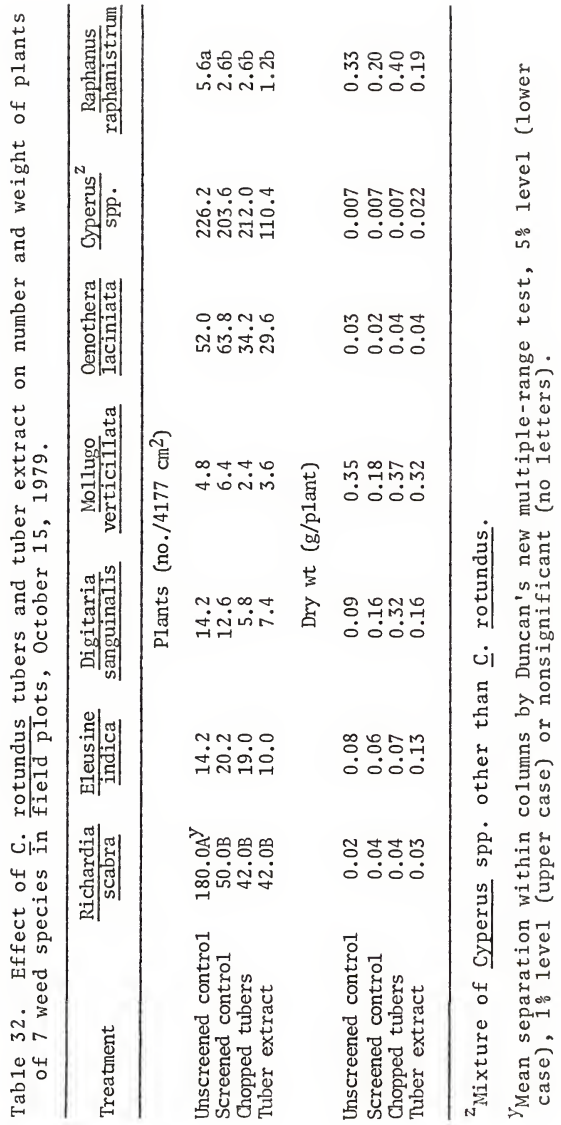




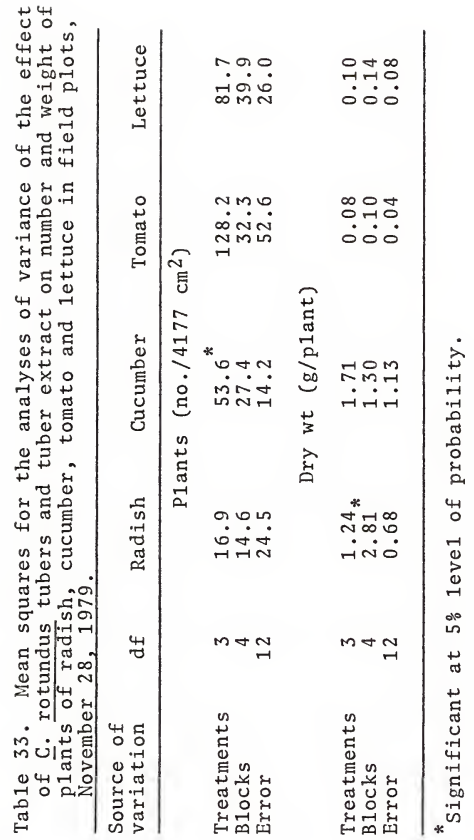




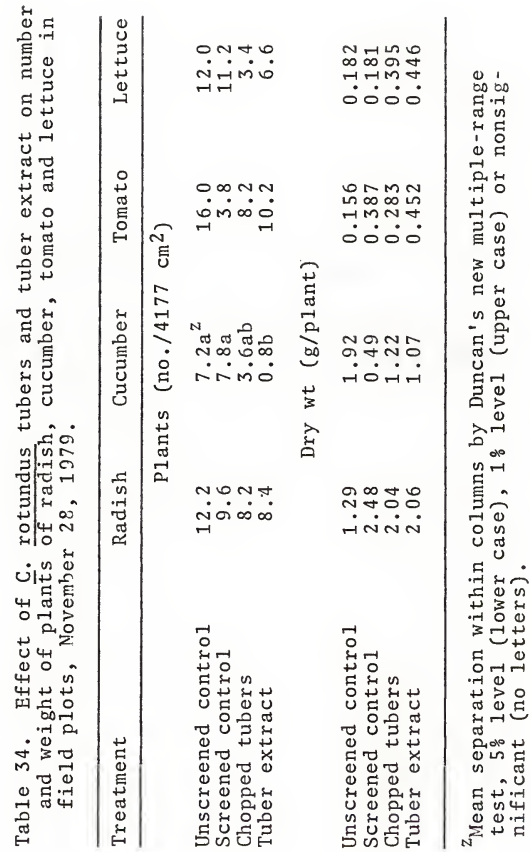




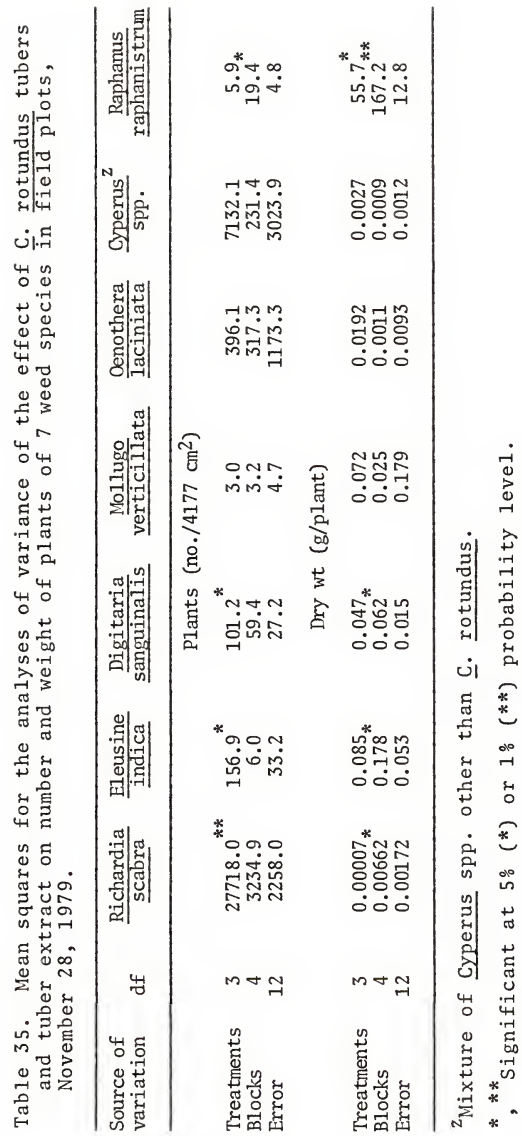




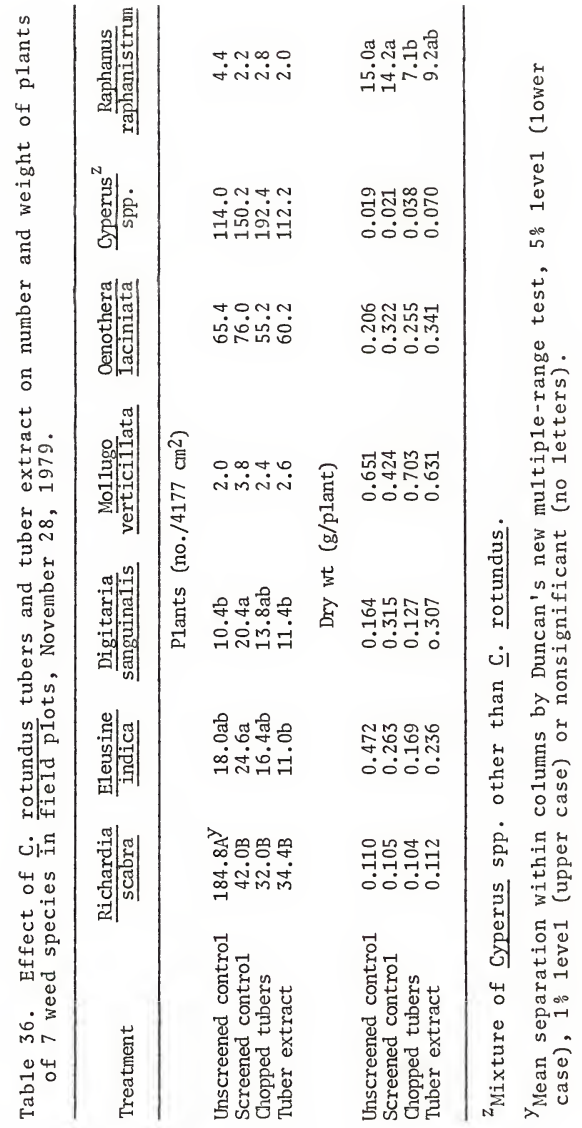


over the screened control, but incorporation of chopped tubers did not. Plant dry weights of the 7 weed spp. were not affected by any treatment, except $\underline{R}$. raphanistrum dry weights were reduced over the controls by incorporation of chopped tubers. Although the tuber extract treatment reduced dry weight of this species, the reduction was not significant relative to the control.

\section{$\underline{\text { Laboratory Studies }}$}

Bioassays--Experiment IV

First bioassay

Extracts of nutsedge leaves and tubers were bioassayed for biological activity by cucumber seed germination (Tables 37 and 38). Four milliliters of extracts of $28 \mathrm{~g}$ of leaves and tubers of nutsedge in $100 \mathrm{ml} \mathrm{CH}_{3} \mathrm{OH}$ completely inhibited cucumber seed germination. Percent and rate of germination (based on radicle emergence) of cucumber seed in the $\mathrm{CH}_{3} \mathrm{OH}$ and water control treatments were similar. When germination was defined as emergence of both radicle and plumule, cucumber seed in the $\mathrm{CH}_{3} \mathrm{OH}$ control had a significantly slower germination rate than in the water control.

Second bioassay

Extracts of 3 quantities of nutsedge tubers were compared for biological activity. These tuber extracts significantly decreased germination percentages, germination rates 
Table 37. Mean squares for the analyses of variance of the influence of $\mathrm{C}$. rotundus tissue extracts on cucumber seed germination.

\begin{tabular}{|c|c|c|c|c|c|}
\hline \multirow{2}{*}{$\begin{array}{l}\text { Source of } \\
\text { variation }\end{array}$} & \multirow[b]{2}{*}{$\mathrm{df}$} & \multicolumn{2}{|c|}{$\begin{array}{l}\text { Germination } \\
\left(\frac{\%}{0}\right)^{z}\end{array}$} & \multicolumn{2}{|c|}{ 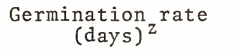 } \\
\hline & & A & B & A & B \\
\hline Treatments & 3 & $12691.7^{* *}$ & $12691.7^{* *}$ & $5.4006^{* *}$ & $27.12^{* *}$ \\
\hline Error & 12 & 25.0 & 25.0 & 0.0006 & 0.05 \\
\hline
\end{tabular}

${ }^{z}$ Germination was defined as A) radicle emergence greater than $3 \mathrm{~mm}$, or $B$ ) radicle and plumule emergence.

*** Significant at $5 \%(*)$ or $1 \%(* *)$ probability level. 
Table 38. Influence of $C$. rotundus tissue extracts on cucumber seed germination.

\begin{tabular}{|c|c|c|c|c|}
\hline \multirow[b]{2}{*}{ Treatment } & \multicolumn{2}{|c|}{$\underset{(\%)^{z}}{\operatorname{Germination}}$} & \multicolumn{2}{|c|}{$\underset{\text { (days) }}{\operatorname{Germination}} \mathrm{rate}$} \\
\hline & $\mathrm{A}$ & B & A & B \\
\hline Leaves $(28 \mathrm{~g})$ & $\mathrm{OB}^{\mathrm{Y}}$ & $\mathrm{OB}$ & $\mathrm{OB}$ & $\mathrm{OB}$ \\
\hline Tubers $(28 \mathrm{~g})$ & $\mathrm{OB}$ & $\mathrm{OB}$ & $O B$ & OC \\
\hline Control $\left(\mathrm{CH}_{3} \mathrm{OH}\right)$ & $100 \mathrm{~A}$ & $100 \mathrm{~A}$ & $2 \mathrm{~A}$ & $4.9 \mathrm{~A}$ \\
\hline Control & $95 \mathrm{~A}$ & $95 \mathrm{~A}$ & $2 \mathrm{~A}$ & $4.1 \mathrm{~B}$ \\
\hline
\end{tabular}

${ }^{\mathrm{z}}$ Germination was defined as A) radicle emergence greater than $3 \mathrm{~mm}$, or B) radicle and plumule emergence.

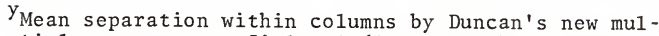
tiple-range test, $5 \%$ leve 1 (lower case), $1 \%$ leve 1 (upper case) or nonsignificant (no letters). 
(based on radicle emergence) and root lengths of cucumber (Table 39). Germination, based on radicle emergence, was reduced from $100 \%$ with the $\mathrm{CH}_{3} \mathrm{OH}$ control to $70 \%$ with the 2.5 $g$ tuber extract (Table 40). Extracts of the lower rates of tubers had no effect on germination percentage. When germination was defined as emergence of radicle and plumule, all 3 rates of tuber extracts reduced germination with the greatest reduction resulting from the $2.5 \mathrm{~g}$ tuber extract. Percent germination and germination rate (both definitions) were similar for the 2 control treatments. Extracts of 0.5 and $2.5 \mathrm{~g}$ of tubers increased the time required for cucumber germination (radicle emergence). Germination took significantly longer with the $2.5 \mathrm{~g}$ tuber extract than with the 0.5 $g$ rate. Cucumber root length was significantly less with the 3 tuber extracts than the 2 control treatments with the shortest roots occurring in the $2.5 \mathrm{~g}$ tuber extract. Also, the water control produced roots significantly shorter than those in the $\mathrm{CH}_{3} \mathrm{OH}$ control.

\section{Experiment V}

$\mathrm{CH}_{3} \mathrm{OH}$ extracts of soil and leachates of sand and soil in which nutsedge had previously grown were bioassayed by seed germination to determine if residual quantities of allelopath existed in the media. Along with the usual control treatment, an extract control, consisting of an extract of Wauchula f.s. in which nutsedge had not grown, was included for comparison purposes. Thus, the extract of 


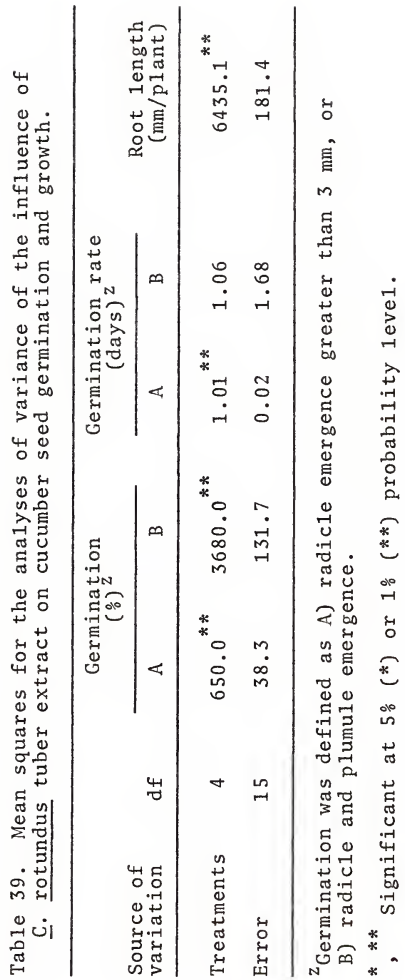




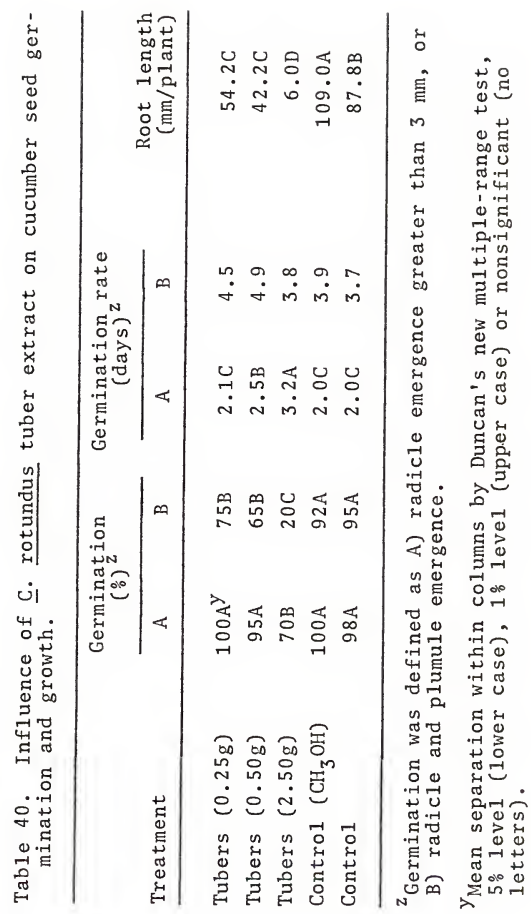


nutsedge infested soil was compared with its own control, and the extract control could be compared with the $\mathrm{CH}_{3} \mathrm{OH}$ control to determine if there were any deleterious extractable substances in noninfested soil. Since differences did exist between the 2 controls, the extract of nutsedge infested soil was only compared to the extract control.

Percent germination, rate of germination (radicle and plumule emergence basis only), root length and fresh weight of tomato and all parameters of lettuce growth, except fresh weight, were significantly affected by the treatments (Table 41). All treatments reduced percent germination (radicle emergence) of tomato over the control (Table 42). Leachates of both soil and sand previously infested with nutsedge significantly reduced germination percentages of tomato. The greatest reduction over the control was in response to the sand leachate. No significant differences in percent germination of tomato were noted between the extract of infested soil and the extract of noninfested soil, regardless of how germination was defined. When defined as emergence of radicle and plumule, germination percentage of tomato was not significantly affected by any treatment relative to that treatment's respective control, even though the leachates of sand and soil infested with nutsedge completely inhibited germination. Leachate of nutsedge infested sand significantly reduced root length of tomato, but leachate of infested soil did not. No significant differences in germination rate or root length of tomato existed between the extracts of 


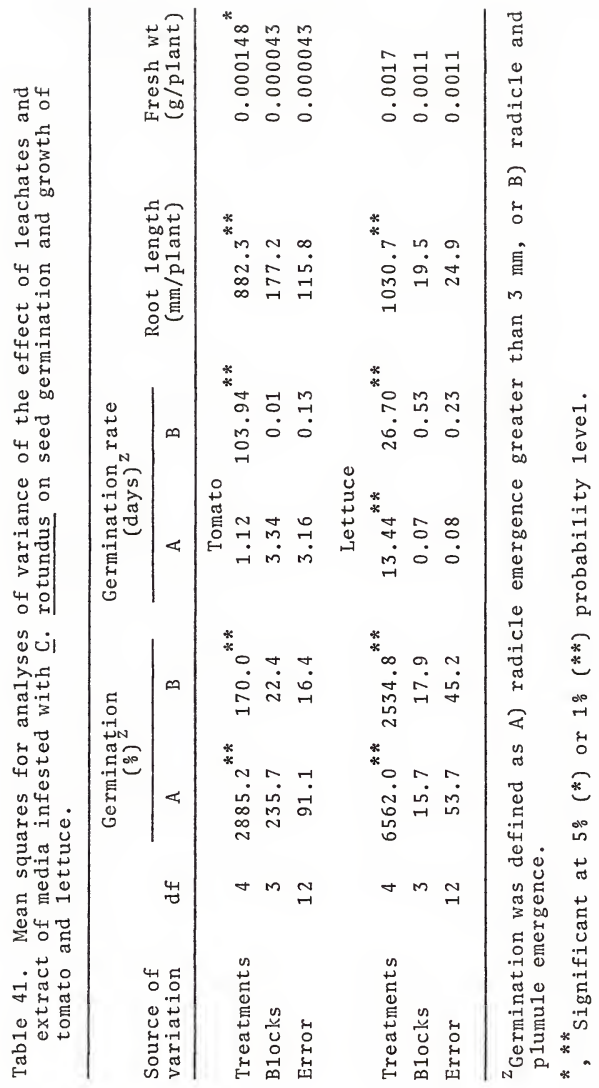




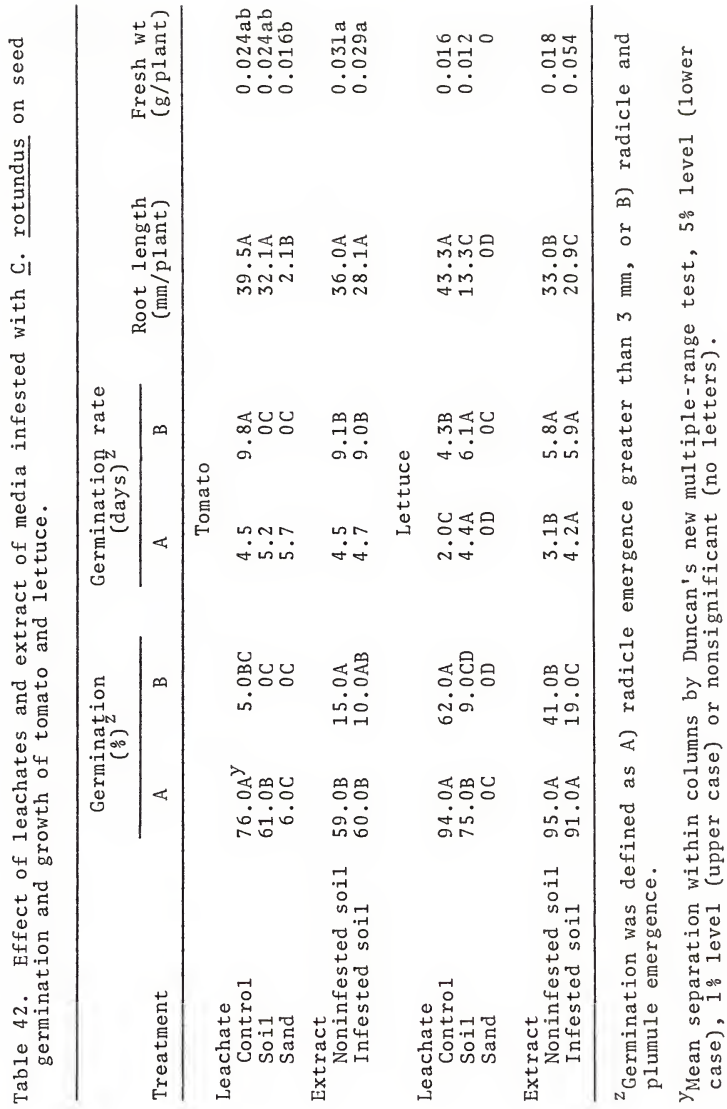


infested and noninfested soil. Leachate of sand in which nutsedge had grown reduced tomato plant fresh weight compared to the extracts of infested and noninfested soil.

Leachates of sand and soil infested with nutsedge significantly reduced germination percentage and rate and root length of lettuce. Leachate of sand completely inhibited germination. Although no significant differences in percent germination of lettuce existed between the extracts of nutsedge infested and noninfested soil when based on radicle emergence, when germination was defined as emergence of both radicle and plumule, the extract of soil in which nutsedge had grown significantly reduced germination percentage of lettuce over the extract of soil not infested with nutsedge. In the case of germination rate, the opposite was true, that is, when germination was defined as radicle emergence, the infested soil extract significantly reduced the rate of germination, but when based on emergence of radicle and plumule, there was no significant difference between the extracts of infested and noninfested soil. Extract of nutsedge infested soil significantly reduced seedling root length of lettuce compared to both control treatments.

Heat Stability - - Experiment VI

Since most proteins are denatured by temperatures in excess of $50^{\circ} \mathrm{C}$, a $60^{\circ} \mathrm{C}$ heat treatment was applied to an extract of nutsedge tubers for 1 hour, then the heated extract was bioassayed for biological activity by a cucumber 
seed germination bioassay. This heated extract was compared to an unheated tuber extract and a control treatment.

Emergence of both radicle and plumule was significantly influenced by treatment, but emergence of radicle alone was not (Table 43). Both the heated and unheated extract treatments reduced radicle length and emergence of radicle and plumule of cucumber (Table 44). Cucumber seed germinated slower in the heated and unheated extracts than in the control when germination was defined as emergence of both radicle and plumule. Where germination was based on emergence of radicle alone, the unheated extract reduced the rate of germination over the control, but was not significantly different from the unheated extract treatment. In no case was there any significant difference between the heated and unheated extract treatments, thus indicating that the inhibitor is heat stable and most probably not proteinaceous.

Water Solubility - Experiment VII

Since the solubility of growth regulating compounds in water can be an important characteristic, a cucumber seed germination bioassay was conducted to determine the water solubility of the allelopath contained in a $\mathrm{CH}_{3} \mathrm{OH}$ extract of nutsedge tubers. Germination and growth of cucumber were significantly influenced by treatment (Table 45). Although the water soluble fraction of tuber extract significantly reduced percent germination of cucumber when germination was based on emergence of radicle and plumule, no significant 


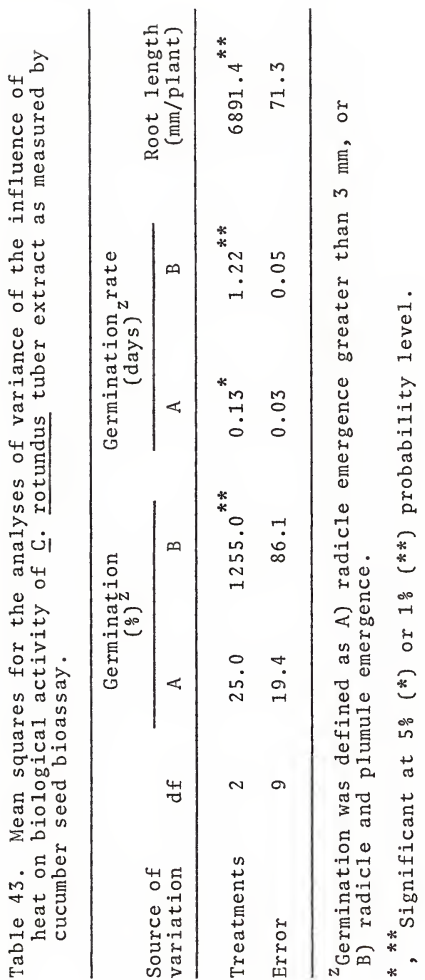




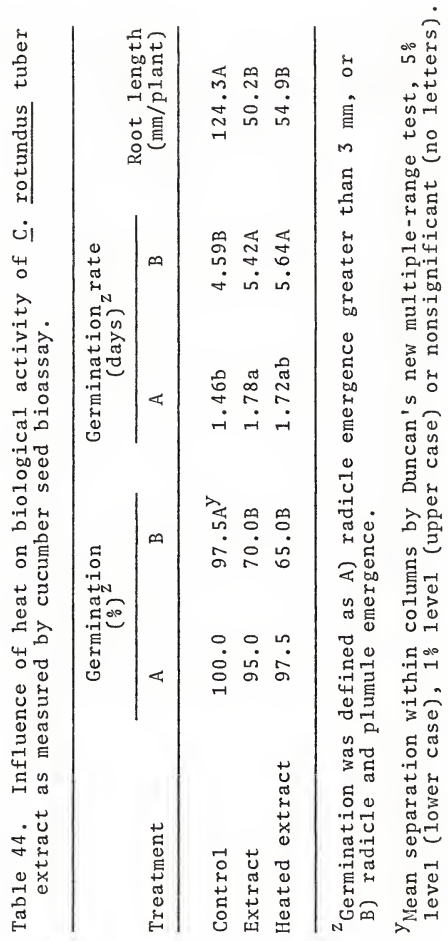




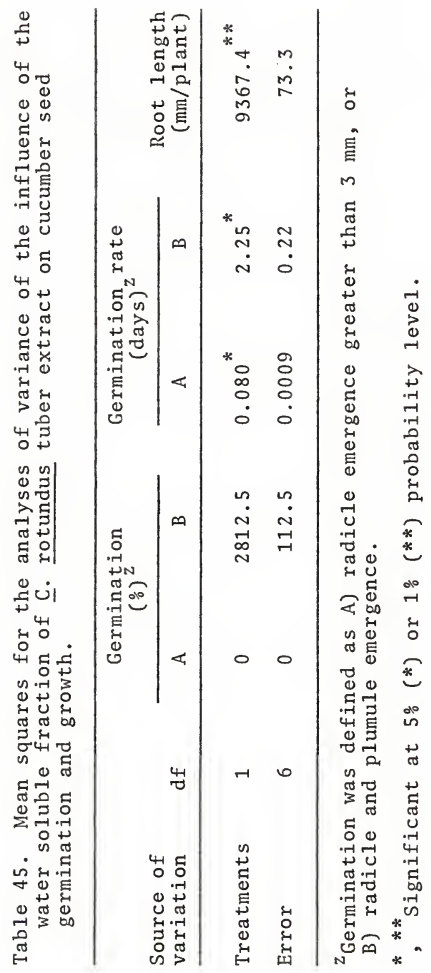


differences occurred between treatments when germination was defined as radicle emergence only (Table 46). The water soluble fraction also increased the time required to germinate and reduced the length of cucumber seedling roots to less than half that of the control. Thus, the inhibitor is at least partially water soluble.

Ge1 Chromatography--Experiment VIII

Gel chromatography was employed to determine the approximate molecular weight (m.w.) of the allelopath. The column calibration curve, established by chromatography of several compounds of known molecular weight is presented in Fig. 1. From this calibration curve, a regression equation was derived relating elution volume $\left(\mathrm{V}_{\mathrm{e}}\right)$ in milliliters to molecular weight as follows: $\log ^{-1}\left(\left(V_{e}-413.8\right) / 127.7\right)$. The inhibitor elution profile (Fig. 2), constructed from average values of 2 chromatographic separations, showed little inhibition of cucumber root growth before $90 \mathrm{ml}$ of solvent had eluted. A large increase in inhibitory activity was observed after $94 \mathrm{~m} 1$ of eluant with a peak of maximum inhibition at $110 \mathrm{ml}$. Inhibition of root growth then dropped off rapidly to less than $10 \%$ by the time $128 \mathrm{~m} 1$ had eluted from the column. Since a broad peak was obtained, the elution volume at which maximum inhibition of cucumber root growth occurred was determined from the inhibitor elution profile using the arithmetic average of the elution volumes of the 5 most inhibitory fractions. This average elution volume was calculated to be 


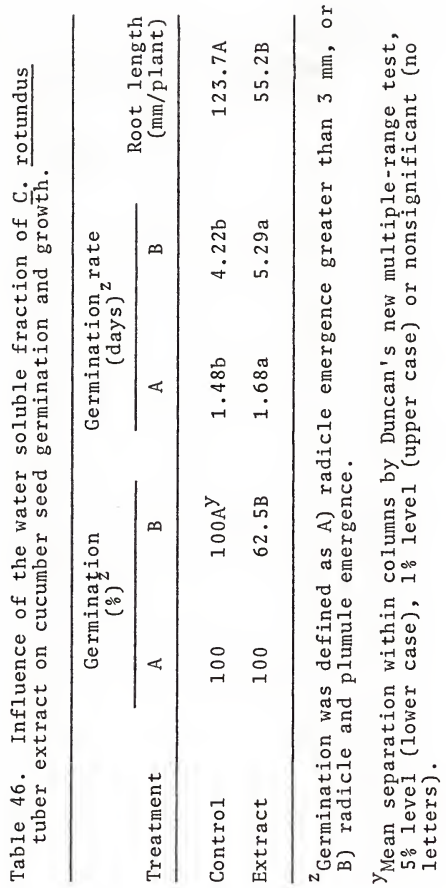




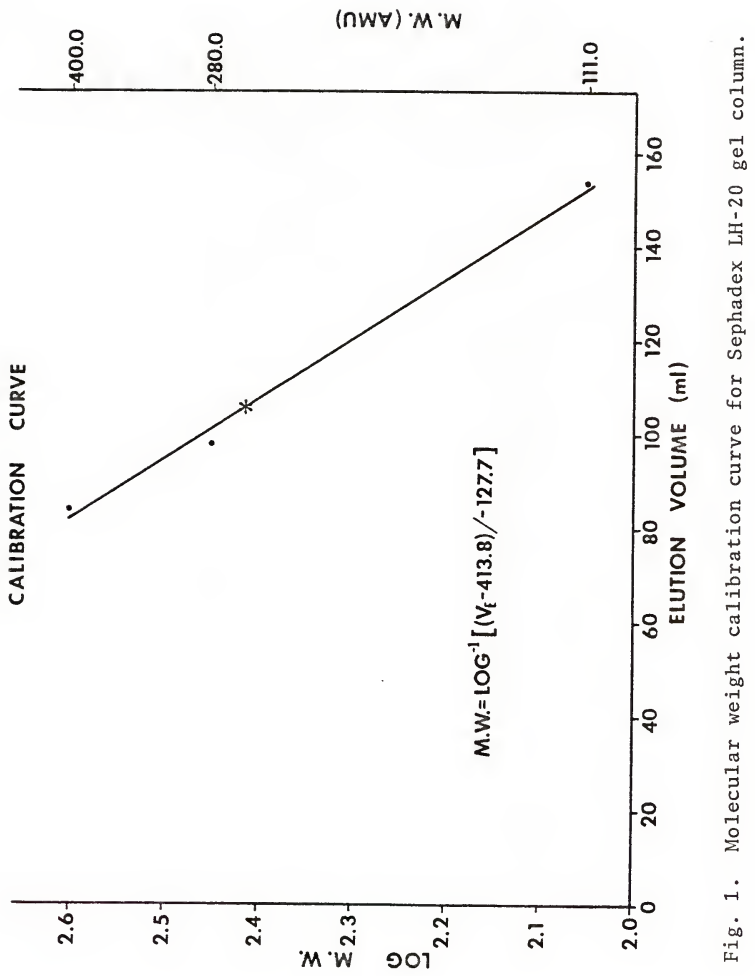




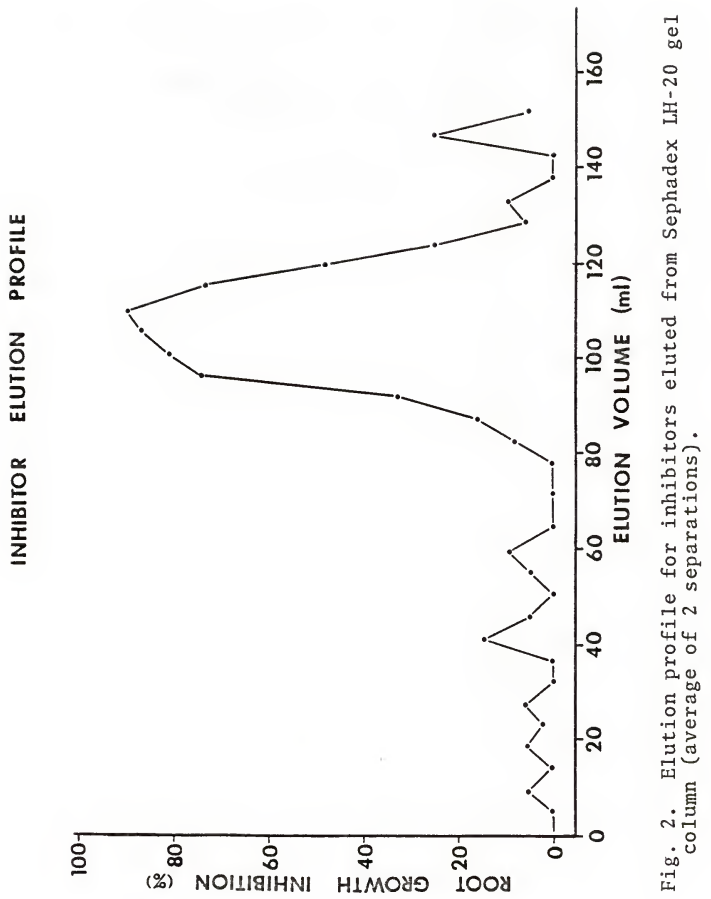


$105.7 \mathrm{~m} 1$. The approximate molecular weight was then calculated from elution volume by using the regression equation. It was thus determined that the inhibitor(s) had molecular weight(s) of approximately 250 atomic mass units (amu) or daltons.

Mass Spectrometric Analys is--Experiment IX

Analysis of the combined sample of the 3 most inhibitory fractions from the gel column by mass spectrometry indicated a mixture of compounds. Two of these compounds were identified as protocatechuic acid and linoleic acid. In addition to these 2 compounds, there were several more compounds which were not identified.

Bioassay of acids

Determination of linoleic and protocatechuic acids as inhibitors and their effective concentrations required bioassay of pure samples of them, alone and in combination, at various concentrations. The bioassay employed was a cucumber seedling root growth bioassay.

Significant differences in root length of cucumber seedlings occurred between treatments at concentrations of 100,500 and $5000 \mathrm{ppm}$, but not at $1000 \mathrm{ppm}$ (Table 47). At $100 \mathrm{ppm}$ the combination treatment increased cucumber root length to a level above that of the 2 acids alone, but was not significantly different from the control (Table 48). Protocatechuic acid at 500 ppm significantly decreased cucumber root length, but neither linoleic acid alone nor in combination with protocatechuic acid had a significant effect 


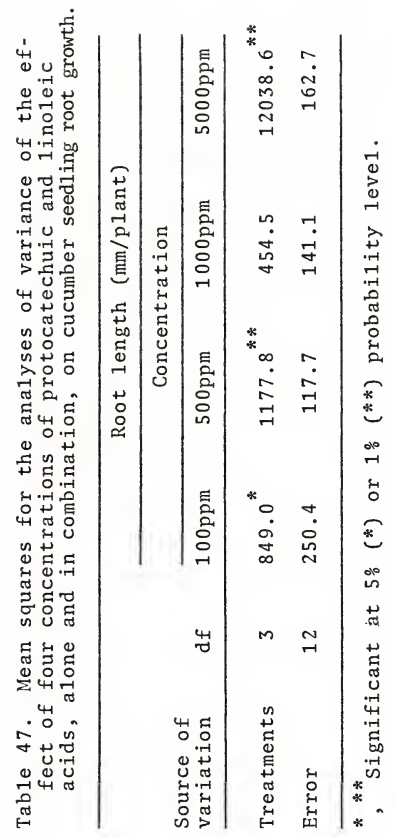




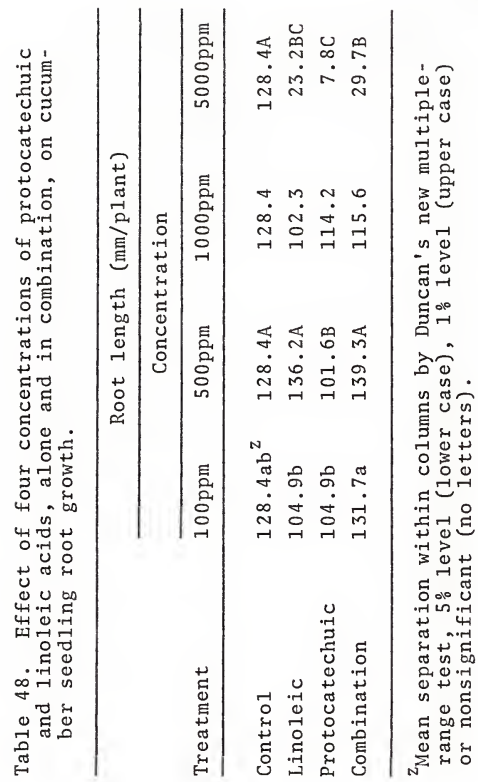


on root length. At concentrations of $5000 \mathrm{ppm}$, all 3 acid treatments significantly reduced cucumber root growth with the greatest reduction resulting from protocatechuic acid alone.

High Pressure Liquid Chromatography - Experiment X

High pressure liquid chromatography (HPLC) was chosen as a means of separating the allelopath(s) in tuber extracts from any associated compounds. Nutsedge tuber extract was fractionated on a silica cartridge (Sep-pak) with solvents of increasing polarity prior to liquid chromatographic separation to improve the separation by HPLC. Cucumber root length bioassay of the polarity group fractions, unfractionated tuber extract and a control treatment demonstrated significant treatment effects (Table 49). The unfractionated tuber extract, first $\mathrm{CH}_{2} \mathrm{Cl}_{2}$ fraction, $60 \% \mathrm{CH}_{3} \mathrm{OH}$ fraction and first $100 \% \mathrm{CH}_{3} \mathrm{OH}$ fraction significantly reduced cucumber root length over the control (Table 50). There was no significant difference in root lengths between the $60 \%$ and first $100 \% \mathrm{CH}_{3} \mathrm{OH}$ fractions; however, the first $\mathrm{CH}_{2} \mathrm{Cl}_{2}$ fraction significantly reduced cucumber root length over these $2 \mathrm{CH}_{3} \mathrm{OH}$ fractions. There was no significant difference in seedling root length between the first $\mathrm{CH}_{2} \mathrm{Cl}_{2}$ fraction and the unfractionated tuber extract. These findings suggested the existence of 2 or more allelopathic compounds in nutsedge tuber extracts. 
Table 49. Mean squares for the analysis of variance of the effect of fractions of C. rotundus tuber extract eluted from a sil. ica cartridge (Sep-pak) on cucumber seedling root length.

\begin{tabular}{lcc}
\hline $\begin{array}{l}\text { Source of } \\
\text { variation }\end{array}$ & df & $\begin{array}{c}\text { Root length } \\
(\mathrm{mm} / \text { plant) }\end{array}$ \\
\hline Treatments & 15 & $2635.4^{* *}$ \\
Blocks & 2 & 352.9 \\
Error & 30 & 245.5 \\
\hline$* * * \begin{array}{l}\text { Significant at } \\
\text { bility level. }\end{array}$ & $(*)$ or $1 \%(* *)$ proba- \\
\end{tabular}


Table 50. Effect of fractions of C. rotundus tuber extract eluted from a silica cartridge (Sep-pak) on cucumber seedling root length.

\begin{tabular}{lc} 
Eluting solvent & $\begin{array}{c}\text { Root length } \\
(\mathrm{mm} / \mathrm{plant})\end{array}$ \\
\hline
\end{tabular}

Control

None (tuber extract)

Methylene chloride-1

Methylene chloride-2

Methylene chloride-3

Methylene chloride-4

Methylene chloride-5

$5 \%$ diethyl ether

$5 \%$ ethyl acetate

$5 \%$ acetone

$4 \%$ methanol

$10 \%$ methano 1

$20 \%$ methano 1

$60 \%$ methano 1

$100 \%$ methanol-1

$100 \%$ methanol-2
$96.2 \mathrm{~A}^{\mathrm{Z}}$

$3.1 \mathrm{D}$

$4.3 \mathrm{D}$

74.2ABC

$80.4 \mathrm{AB}$

$89.4 \mathrm{AB}$

$96.0 \mathrm{~A}$

$91.4 \mathrm{AB}$

$81.2 \mathrm{AB}$

$84.2 \mathrm{AB}$

84. $0 \mathrm{AB}$

$89.5 A B$

$91.1 \mathrm{AB}$

$61.9 B C$

$47.8 \mathrm{C}$

$86.2 \mathrm{AB}$

'Mean separation by Duncan's new multiplerange test, $5 \%$ level (lower case), 1\% level (upper case) or nonsignificant (no letters). 
Each inhibitory silica cartridge fraction was evaporated to dryness, resolubilized in $1 \mathrm{ml} \mathrm{CH}_{3} \mathrm{OH}$, chromatographed on an HPLC and the resultant eluant fractions bioassayed. None of the HPLC fractions significantly altered cucumber seedling root length compared to the control treatment (Tables 51 and 52).

Since the concentration of the compounds in the silica cartridge eluants was approximately 1.66 times that in the sample loaded onto the HPLC, a cucumber root length bioassay was conducted comparing the control treatment and an unfractionated tuber extract with $1 \mathrm{~m} 1$ of each inhibitory silica cartridge fraction diluted to the equivalent concentration by bringing $1 \mathrm{~m} 1$ to a final volume of $1.66 \mathrm{~m} 1$ with the appropriate solvent. Comparison of root growth in the control treatment with that in the diluted silica cartridge fractions would determine whether the lack of inhibition of root growth by the HPLC fractions was due to a concentration effect or not. The first $\mathrm{CH}_{2} \mathrm{Cl}_{2}$ and $100 \% \mathrm{CH}_{3} \mathrm{OH}$ and the $60 \%$ $\mathrm{CH}_{3} \mathrm{OH}$ significantly reduced cucumber root growth when compared with the control (Tables 53 and 54 ). The first $\mathrm{CH}_{2} \mathrm{Cl}_{2}$ fraction was as inhibitory as the unfractionated tuber extract and significantly more inhibitory than the $60 \%$ and first $100 \% \mathrm{CH}_{3} \mathrm{OH}$ fractions. Thus, the lack of significance between the various HPLC fractions and the control treatment was most 1 ikely not due to a concentration effect. 
Table 51. Mean squares for the analyses of variance of the effect of fractions of $\underline{C}$. rotundus tuber extract separated by liquid chromatography on cucumber seedling root length.

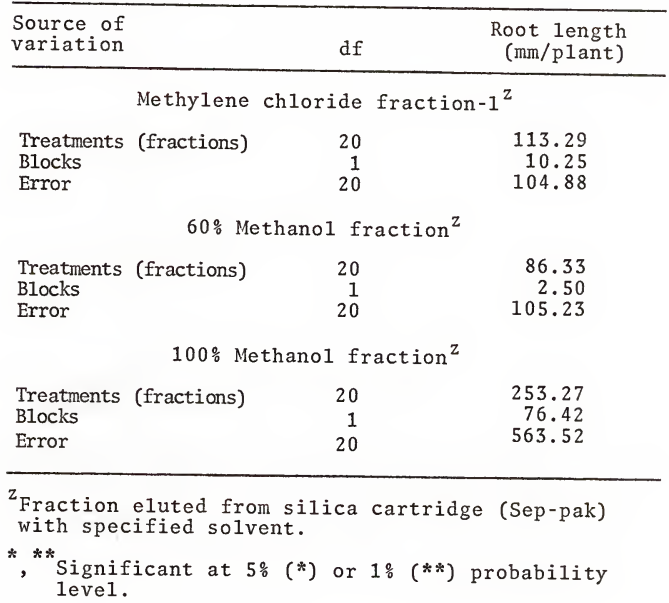


Tab1e 52. Effect of fractions of C. rotundus tuber extract separated by liquid chromatography on cucumber seedling root length.

\begin{tabular}{|c|c|c|c|}
\hline \multirow[b]{3}{*}{$\begin{array}{c}\text { Fraction } \\
\text { no. }\end{array}$} & \multicolumn{3}{|c|}{ Root length (mm/plant) } \\
\hline & \multicolumn{3}{|c|}{ Silica cartridge (Sep-pak) fraction } \\
\hline & $\begin{array}{l}\text { Methylene } \\
\text { chloride-1 }\end{array}$ & $\begin{array}{l}\quad 60 \% \\
\text { Methanol }\end{array}$ & $\begin{array}{l}100 \% \\
\text { Methano1-1 }\end{array}$ \\
\hline 1 & 115.2 & 113.6 & 116.4 \\
\hline 2 & 114.4 & 123.9 & 112.5 \\
\hline 3 & 124.1 & 128.9 & 111.8 \\
\hline 4 & 126.1 & 117.1 & 125.5 \\
\hline 5 & 126.8 & 122.6 & 117.0 \\
\hline 6 & 116.5 & 128.6 & 121.0 \\
\hline 7 & 107.5 & 114.5 & 114.8 \\
\hline 8 & 115.6 & 118.2 & 121.4 \\
\hline 9 & 119.8 & 126.1 & 115.1 \\
\hline 10 & 125.9 & 126.8 & 123.8 \\
\hline 11 & 123.6 & 117.4 & 120.8 \\
\hline 12 & 115.4 & 117.0 & 124.4 \\
\hline 13 & 111.6 & 111.8 & 121.1 \\
\hline 14 & 109.4 & 115.0 & 123.5 \\
\hline 15 & 100.0 & 117.9 & 108.9 \\
\hline 16 & 117.8 & 121.5 & 114.1 \\
\hline 17 & 112.6 & 120.0 & 130.4 \\
\hline 18 & 125.9 & 114.1 & 118.2 \\
\hline 19 & 113.1 & 120.8 & 123.9 \\
\hline 20 & 112.8 & 107.5 & 83.0 \\
\hline Control & 103.6 & 103.6 & 103.6 \\
\hline
\end{tabular}


Table 53. Mean squares for the analyses of variance of the effect of diluted fractions of $C$. rotundus tuber extract eluted from a silica cartridge (Sep-pak) on cucumber seedling root length.

\begin{tabular}{lcc}
\hline $\begin{array}{l}\text { Source of } \\
\text { variation }\end{array}$ & df & $\begin{array}{c}\text { Root length } \\
(\mathrm{mm} / \mathrm{plant})\end{array}$ \\
\hline Treatments (fractions) & 4 & $6155.8 * *$ \\
Blocks & 3 & 25.4 \\
Error & 12 & 46.6 \\
\hline$* * *$ Significant at $5 \%(*)$ & or $1 \%(* *)$ probability level.
\end{tabular}


Table 54. Effect of diluted fractions of C. rotundus tuber extract eluted from a silica cartridge (Sep-pak) on cucumber seedling root length.

\begin{tabular}{lc}
\hline Eluting solvent & $\begin{array}{c}\text { Root length } \\
(\mathrm{mm} / \mathrm{plant})\end{array}$ \\
\hline Control & $98.0 \mathrm{~A}^{\mathrm{z}}$ \\
None (tuber extract) & $4.2 \mathrm{C}$ \\
Methylene chloride & $11.6 \mathrm{C}$ \\
$60 \%$ Methanol & $65.4 \mathrm{~B}$ \\
$100 \%$ Methanol & $58.8 \mathrm{~B}$ \\
\hline
\end{tabular}

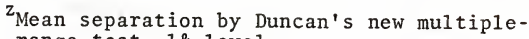
range test, $1 \%$ leve1. 


\section{DISCUSSION}

\section{Greenhouse Studies: Experiment I}

Cucumber, lettuce and tomato plants are very sensitive to a wide range of growth regulating compounds and, as such, often make good bioassay or indicator species. In these experiments growth of plants of these 3 species demonstrated that purple nutsedge was capable of growth interference by both competitive and allelopathic means. Any attempt to determine if allelopathic effects were involved in growth reduction required removal of competition as a component of interference. In these studies, growth reductions in upper crocks reflect total interference that consisted of both competition and allelopathy. Reductions in growth of plants in lower crocks should have been due to allelopathy alone.

Cucumber Plantings

Growth of cucumber in the various plantings varied considerably. Allelopathic growth reductions were found and the level of reduction varied with season. Reductions of cucumber plant growth in upper crocks containing growing $\underline{\mathrm{C}}$. rotundus plants were products of competition and possibly allelopathy. Growth reductions in upper crocks due to decaying tubers and leaves may have been the result of immobilization of nitrogen by associated microorganisms, microbial pathogens or an allelopathic compound. Decreases in cucumber growth in lower crocks could only be due to allelopathic 
effects or nutritional deficiencies. Nutritional problems can be ruled out since there were no reductions in cucumber growth in lower crocks corresponding to reductions in growth of cucumbers in upper crocks in the first 3 plantings (spring and summer planting dates). If reductions in cucumber growth in lower crocks were due to nutritional disorders, then cucumbers receiving leachate from growing plants and decaying tissues of nutsedge would have had their growth decreased. Since this was not the case in the first 3 plantings and reductions in cucumber growth in lower crocks in plantings 6,7 and 8 (fall and winter planting dates) were not accompanied by reductions in cucumber growth in upper crocks, it can be assumed that nutrition supplied to the plants was adequate, and cucumber growth reductions in lower crocks were due to a leachable allelopathic substance.

The improbability that microbial pathogens were responsible for reductions in cucumber plant growth is evidenced by the fact that in the last 3 plantings there were growth reductions in lower crocks receiving leachates from decaying tubers and leaves of nutsedge without corresponding reductions in cucumber growth in upper crocks. Thus, these reductions must have been the product of a leachable growth inhibitor. Lack of growth inhibition of cucumber in upper crocks of these 3 plantings as a result of the decaying tissue treatments may have been due to 1) the presence of a growth promoter which is insoluble in water and masking the effect of any inhibitors, or 2) masking effects due to improved 
physical aspects of the medium as a result of organic material additions. The latter seems to be the most plausible explanation, especially since it was only in the last 4 plantings (January 11, September 13 and October 29, 1979, and January 18,1980 ) that this occurred. Organic debris in the medium would have increased with time even though attempts were made to remove these materials before adding fresh tissues for the next planting. Decreases in growth of cucumbers in lower crocks were not observed for the first 3 plantings. This may have been due to a low concentration of inhibitor in $\underline{C}$. rotundus during that season of the year coupled with a low solubility coefficient in water. Thus, the amount of inhibitor present in lower crocks would have been too low to reduce growth. Seasonal variation in inhibitor content of many perennial species exists with concentrations increasing in fall in response to decreasing photoperiod and temperature. If this is the case with $\underline{\mathrm{C}}$. rotundus, maximum growth reductions in cucumbers should be in the fall and winter months. Such a trend is obvious from the data with the exceptions of plantings 4 and 5 (fall and winter). The lack of growth reductions due to leachates from decaying tissues in planting 4 (fall 1978) may have been a result of 1) low concentrations of allelopath in these tissues at the time the treatments were applied, or 2) low solubility of the allelopath caused by lowered temperatures. A decrease in allelopathic activity in planting 5 (winter 1979) may have been related to low greenhouse 
temperatures as there were several prolonged periods of no heat during this time. This hypothesis is further supported by the fact that maximum tuberization of $\underline{C}$. rotundus had been shown to occur in the fall and winter, dropping to a minimum in spring and summer (3). Number of tubers associated with growing plants would thus increase in fall and winter, providing a greater inhibitor concentration. This increased concentration should be and was accompanied by a greater decrease in cucumber p1ant growth where leachates originated from growing plants than where the leachate was obtained from decaying tissue.

\section{Lettuce Plantings}

Lettuce growth reductions in upper crocks were recorded for the growing nutsedge plants and decaying tubers and leaves treatments in both plantings. The fact that lettuce in the January 28,1979 , planting failed to demonstrate allelopathic decreases in growth in lower crocks receiving leachates from tubers and leaves of nutsedge may be explained on the basis of 1) temperature effects as discussed for the fifth cucumber planting, or 2) inhibitor concentration was inadequate to produce significant decreases. Concentration of inhibitor is probably the explanation for the lack of growth reduction in lower crocks receiving leachates from decaying tissues in the April 5, 1979, planting, since these same treatments reduced growth in the upper crock series. A leachable a1lelopath was obviously present in leachates 
entering the lower crocks of the growing nutsedge plants treatment in both plantings. The fact that weight and leaf area of lettuce were affected in the first planting and only emergence rate was decreased in the second suggests a decrease in concentration and/or activity as season changed from winter to spring.

Tomato Plantings

Decreased tomato plant growth in lower crocks receiving leachate from growing nutsedge plants in the Apri1 9, 1979, planting demonstrates the presence of an allelopathic compound. Absence of corresponding decreases in the May 10, 1979 planting suggests a drop in inhibitor concentration or activity as the season progressed from spring into summer. The general lack of activity in both upper and lower crocks due to decaying leaves and tubers may also be related to low inhibitor concentration in these tissues at the time in question. Another distinct possibility for tomato and lettuce plantings is that these species are not as sensitive to the allelopathic compound as are cucumber plants.

The data presented herein indicate that a leachable allelopathic substance is released by decaying tubers and leaves and growing plants of $\underline{\mathrm{C}}$. rotundus. The observed growth reductions due to decaying tubers lend further support to the findings of Horowitz and Friedman $(10,16)$. Furthermore, the data suggest that seasonal variations exist in the concentration and importance of this compound with 
concentration increasing in fall and winter and decreasing in spring and summer. The greater reduction in growth where receiving leachates from growing plants over that from decaying tissues suggests that 1 ) there are more tubers produced by nutsedge plants in upper crocks and thus more inhibitor and/or 2) the allelopathic substance is also released as a root exudate.

\section{Field Studies}

Experiment II

Allelopathic effects of one plant upon another may be manifest as a negative correlation between the number of plants of one species versus those of another. Thus, the significant negative correlation between density of

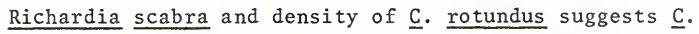
$\underline{\text { rotundus }}$ has an allelopathic effect upon emergence of $\underline{R}$. scabra under field conditions. The positive correlations between $\underline{\text { C. }} \underline{\text { rotundus }}$ and densities of $\underline{E}$. hirta and $\underline{G}$. carolinianum suggest that allelopathy is not involved in determining densities of these species.

Experiment III

Since the plots for the 2 tuber treatments and the screened control were screened to remove $\underline{\underline{C}}$. rotundus tubers while those for the unscreened control were not, the 2 tuber treatments can be compared only to the screened control. Differences between the 2 controls could possibly reflect 
differences due to screening or incidence of $\underline{C}$. rotundus; whereas, a reduction in growth of the bioassay plants as a result of either of the tuber treatments relative to their control would indicate allelopathic effects of the treatment. The only differences noted for the 4 crops on October 15, 1979 were between screened and unscreened controls. The significantly lower number of plants of cucumber and tomato and the reduced percent germination of tomato seed due to screening suggests these reductions are due to changes in the physical and biological properties of the soil. If the growth reduction was due to $\underline{\mathrm{C}}$. rotundus, then one would expect better growth where $\underline{C}$. rotundus was absent. Such was not the case. Most probably, screening the soil resulted in dividing the soil into particle size separates which could have the observed effects upon plant growth. Also, screening would tend to redistribute seeds and microbes in the soil, which could influence plant growth and the no. of weeds present. This same effect was noted for number of plants of $\underline{R}$. scabra and R. raphanistrum in the field plots on October 15, 1979. Reduction in number of cucumber plants on November 28, 1979, by tuber extract indicates the presence of an allelopathic inhibitor in tubers which was potent enough to produce the effects under field conditions. The absence of a corresponding decrease in cucumber plant dry weight suggests either the compound degrades rapidly or is easily leached under field conditions. Decrease in number of $\underline{R}$. scabra plants on November 28,1979 , in plots where soil was screened is suggestive 
of the aforementioned changes in the physical and biological properties of the soil. Increase in number of $\underline{D}$. sanguinalis plants for the same treatment and decrease for the tuber extract treatment indicate $\underline{\mathrm{C}}$. $\underline{\text { rotundus }}$ tubers contain an allelopathic compound and strongly suggest the increase in number of plants in the screened control was due to removal of $\underline{C}$. rotundus plants and tubers as a source of this allelopath. Decreased plant weight of $\underline{R}$. raphanistrum on November 28 , 1979, due to incorporation of chopped nutsedge tubers into the soil demonstrates the presence of an allelopathic compound in tubers which is capable of expressing itself under natural field conditions. This experiment did not substantiate the negative correlation noted in Experiment II between densities of $\underline{\text { C. }}$ rotundus and $\underline{R}$. scabra.

\section{Laboratory Studies: Experiments IV-X}

Inhibition of cucumber seed germination by extracts of $28 \mathrm{~g}$ of leaves and tubers of nutsedge and reductions in cucumber growth produced by extracts of $0.25,0.50$ and $2.5 \mathrm{~g}$ of nutsedge tubers demonstrate the presence of a $\mathrm{CH}_{3} \mathrm{OH}$ soluble growth inhibitor in these tissues. The significant decrease in germination and growth of cucumber as quantity of tuber increases illustrates that as concentration increases so does growth inhibition. Lack of a significant difference in percent germination of cucumber between the $\mathrm{CH}_{3} \mathrm{OH}$ control and water control treatments shows there are no harmful residues from the extracting solvent. 
Decreased percent germination of lettuce and tomato seed and increased time required for germination of tomato seed by sand and soil leachates demonstrates the presence of a leachable allelopath. Also, reduction in percent germination of tomato and lettuce by sand leachate relative to soil leachate suggests that the inhibitor may be retained by soil to a degree. Reductions in tomato root length by sand leachate and lettuce root length by both leachates further demonstrates the presence of a leachable inhibitor. Reduction in germination and root length of lettuce by extract of nutsedge infested soil further substantiates the conclusions of the first laboratory bioassay.

Reduction in percent germination and root length and increase in time required for germination of cucumber seed by heated and unheated extracts of nutsedge tubers and the absence of any significant difference between the 2 extracts for these parameters indicate the inhibitor is heat stable and most probably not protein-based. This would rule out those proteins which have biological activity based on shape or conformation, but not necessarily those whose activity is dependent on a specific amino acid sequence.

Reductions in cucumber seed germination percentage and root length and increase in time required for germination by the water soluble fraction of tuber extract indicates the inhibitor present in $\underline{\mathrm{C}}$. rotundus tubers is at least partially water soluble. Linoleic and protocatechuic acids are both water soluble, thus the results of the water solubility 
experiment lends support to the presence of these acids in the inhibitory fraction.

The approximate molecular weight of the fraction of maximum inhibition was 250 amu as determined by gel chromatography. It should be noted that this value is for the peak and does not reflect the remainder of the elution curve. Thus, the active fractions could contain compounds with weights varying from the approximation by roughly $\pm 100 \mathrm{amu}$. This molecular weight range encompasses many fatty acids, including linoleic acid (280 amu), phenolic acids, such as protocatechuic acid (154 amu), abscisic acid and many other growth inhibitors. Most enzymes and other proteins are considerably larger molecules than this; therefore, most probably proteins are not involved in the observed inhibition as noted in the heat stability experiment.

Although protocatechuic acid and linoleic acid were suggested as constituents of the inhibitory fractions, there were several other component compounds for which suggested identities were not offered. Also, there were some inorganic ionic species in the sample which were complicating or confusing the analysis.

Since reduction in cucumber root length by protocatechuic acid at a concentration of $500 \mathrm{ppm}$ was not followed by reduction for the $1000 \mathrm{ppm}$ rate, the results of the $500 \mathrm{ppm}$ rate must be viewed with skepticism. The significant reduction in root length by the 2 acids, alone and in combination, at a concentration of $5000 \mathrm{ppm}$ indicates these acids 
are capable of reductions in growth at this concentration; however, $5000 \mathrm{ppm}$ is equivalent to $0.5 \%$ by weight and it does not seem likely that either acid, alone or in combination, would normally constitute such a large percentage of the weight of $\underline{\mathrm{C}}$. $\underline{\text { rotundus }}$ tubers. Therefore, it is doubtful that the allelopath in $\underline{\mathrm{C}}$. rotundus tubers is composed of only these 2 acids. It seems more logical to assume that the allelopath is actually several compounds, 2 of which may be protocatechuic and linoleic acid.

Data from bioassay of silica cartradge (Sep-pak) eluants indicates the allelopathic compound is actually 2 or more compounds. One compound has low polarity, while the other is fairly polar. Linoleic acid is low in polarity and protocatechuic acid is relatively polar, thus the polarity description fits these 2 acids.

Lack of root length reductions in the bioassay of HPLC separations of the active fractions eluted from the silica cartridge was not due to a concentration effect. Data suggest that either the inhibitors were retained on the column or each silica cartridge fraction consisted of several compounds which were responsible for the inhibitory activity. The latter seems quite plausible for the following reasons: 1) mass spectrometric analysis suggested the presence of several unidentified compounds and 2) the previously mentioned problems associated with the concentration of the 2 identified compounds, protocatechuic and linoleic acids. If the inhibitor was a complex of compounds, separation from one another 
might produce results such as those obtained, assuming no single compound was capable of reducing growth by a statistically significant amount.

Protocatechuic acid and other phenolic compounds have been isolated from $\underline{\text { C. }}$ rotundus tubers (19) along with inhibitor $\beta$ (52). Any of a number of these compounds have properties similar to those of the unidentified allelopaths. In addition, many of these same compounds are capable of producing similar growth responses when present in sufficient concentrations. Therefore, it is possible that some of these compounds may be involved in the growth reductions noted. Most probably the allelopaths are not proteinaceous, considering the low molecular weight and heat and alcohol stability of the inhibitor. 
Greenhouse studies were conducted to determine if $\underline{\mathrm{C}}$. rotundus plants and residues reduced growth of selected bioassay species by release of an allelopathic compound into the growth medium. Treatments included growing $\underline{\mathrm{C}}$. rotundus plants and decaying residues of leaves and tubers of $\underline{\mathrm{C}}$. $\underline{\text { ro- }}$ tundus.

Growing plants and decaying leaves and tubers of $\underline{C}$. rotundus reduced growth of bioassay species with growing nutsedge plants producing the greatest growth reduction. A seasonal effect was observed with maximum growth reduction of bioassay plants occurring in fall and winter, a time that coincides with the period of maximum nutsedge tuberization.

Two field experiments were conducted to determine if the presence of $\underline{C}$. rotundus reduced the frequency of occurrence of other weed species, and to evaluate tubers and $\mathrm{CH}_{3} \mathrm{OH}$ extracts of tubers as phytotoxins under field conditions. The first experiment was a field weed survey subjected to correlation analysis. In the second experiment, treatments were 1) unscreened soil control, 2) screened soil control, 3) chopped tubers incorporated into screened soil, and 4$) \mathrm{CH}_{3} \mathrm{OH}$ tuber extract incorporated into screened soil. Bioassay crops employed were cucumber, lettuce, tomato and radish. Weed populations were also identified and counted. The presence of $\underline{C}$. $\underline{\text { rotundus }}$ was negatively correlated with $\underline{\text { Richardia scabra and positively correlated with Euphorbia }}$ 
$\underline{\text { hirta }}$ and Geranium carolinianum. Data from the second field experiment indicate the presence of an allelopathic compound in $\underline{C}$. rotundus tubers as evidenced by the reduction in number of cucumber, Eleusine indica and Digitaria sanguinalis plants when grown in soil treated with nutsedge tuber extract and the decrease in Raphanus raphanistrum plant weight where chopped tubers were incorporated into the soil.

Laboratory experiments were conducted to evaluate tubers as the source of the allelopath. Cucumber seed germination bioassays of $\mathrm{CH}_{3} \mathrm{OH}$ tuber extracts demonstrated the presence of a potent growth inhibitor. An allelopathic compound was shown to be present in soil in which $\underline{C}$. rotundus had previously grown. Also, the allelopath was leachable and data suggested the soil was somewhat retentive of it.

Additional laboratory studies were conducted to chemically separate and characterize the inhibitor obtained from tubers. The allelopath was shown to be heat stable and at least partially water soluble. Gel chromatography of tuber extract determined it had a molecular weight of approximately 250 amu or daltons.

Mass spectrometric analysis of inhibitory fractions of tuber extract obtained by ge1 chromatography suggested constituents included protocatechuic and linoleic acids. A number of other compounds and some inorganic ions were also present, but were not identified. A cucumber seed germination bioassay was performed on these 2 acids alone and in 
combination at concentrations of 100, 500, 1000 and $5000 \mathrm{ppm}$. Both acids and the combination were inhibitory at $5000 \mathrm{ppm}$.

Further separation of allelopathic constituents of tuber extract was attempted by employing high pressure liquid chromatography preceded by a separation procedure based on elution by a solvent sequence of increasing polarity. The a11elopath consisted of 2 or more compounds, one of which was low in polarity, while the other was fairly polar. Attempts to further separate these components by high pressure liquid chromatography were not successful. It is suggested that the allelopath may actually be a complex of compounds that are water soluble, heat stable and have molecular weights of approximately $250 \pm 100 \mathrm{amu}$. 


\section{LITERATURE CITED}

1. Be11, D. T. and D. E. Koeppe. 1972. Noncompetitive effects of giant foxtail on the growth of corn. Agron. J. $64: 321-325$.

-2. Benda11, G. M. 1975. The a11elopathic activity of California thistle (Cirsium arvense (L.) Scop.) in Tasmania. Weed Res. 15:77-81.

.3. Betria, A. I. and E. R. Monta1di. 1975. Tuber production by purp1e nutgrass (Cyperus rotundus L.) in darkness. Weed Res. 15:73-76.

4. Bode, H. R. 1940, Uber die b1attausscheidungen des vermuts und ihre werkung auf andere pflanzen. P1anta $30: 567-589$.

5. Bonner, J. and A. W. Ga1ston. 1944. Toxic substances from the culture media of guayule which may inhibit growth. Bot. Gaz. 106:185-198.

6. Cook, M. T. 1921. Wilting caused by wa1nut trees. Phytopathology 11:346.

7. Dommerques, Y. 1954. Biologie des sols forestiers du centre et de 1 'est de Madagascar. Trans. Int. Cong. Soi1 Sci. 5th 3:24-28.

8. Eden, T. 1951. Some agricu1tura1 properties of Cey1on montane tea soils. J. Soil Sci. 2:43-49.

9. Ferna1d, M. L. 1950. Gray's manual of botany, 8 th edition. American Book Company, New York.

10. Friedman, T. and M. Horowitz. 1970. Phytotoxicity of subterranean residues of three perennial weeds. Weed Res. $10: 382-385$.

11. Funke, G. L. 1943. The influence of Artemisia absinthium on neighbouring plants. Blumea 5:281-293.

12. Gressel, J. B. and L. G. Ho1m. 1964. Chemica1 inhibition of crop germination by weed seeds and the nature of inhibition by Abutilon theophrasti. Weed Res. 4:44-53.

13. Harborne, J. B. and N. W. Simmonds. 1964. The natura1 distribution of the phenolic ag1ycones. pp.129-169 In J. B. Harborne, ed. Biochemistry of phenolic compounds. Academic Press, New York. 
014. Hauser, E. W. 1962. Estab1ishment of nutsedge from space-planted tubers. Weeds 10:209-212.

15. Holm, L. and J. Herberger. 1969. The world's worst weeds. Proc. Asian-Pacific Weed Soc. Conf. 2nd 1-17.

16. Horowitz, M. and T. Friedman. 1971. Biologica1 activity of subterranean residues of Cynodon dacty1 on L., Sorghum halepense L. and Cyperus rotundus L. Weed Res. $11: 88-93$.

17. Jacquemin, H. and Y. Berlier. 1956. Evolution du pouvoir nitrifiant d'um sol de basse Cote D'Ivoirie sous 1 'action du c1imat et de la vegetation. Trans. Int. Cong. Soil Sci. 6th C:343-347.

18. Junttila, 0. 1975. A1lelopathy in Heracleum laciniatum: inhibition of lettuce seed germination and root growth. Physio1. P1ant. 33:22-27.

19. Komai, K. and K. Ueki. 1975. Polyphenolic substances in Cyperus rotundus $\mathrm{L}$. and Cyperus serotinus Rottb. Proc. Asian-Pacific Weed Sci. Conf. 5 th 74-77.

20. Leopo1d, A. C. and P. E. Kriedemann. 1975. In P1ant growth and development. McGraw-Hill Book Co., New York. pp. $113-116$.

21. Likens, G. E., F. H. Bormann, and N. M. Johnson. 1969. Nitrification: importance to nutrient losses from a cutover forested ecosystem. Science 163:1205-1206.

22. Lockerman, R. H. and A. R. Putnam. 1977. Suppression of weeds with allelopathic accessions of cucumber. Abstracts Weed Sci. Soc. Amer. 42: no. 86.

23. Lohdi, M. A. K. 1975. Allelopathic effects of hackberry in a bottomiand forest community. J. Chem. Ecol. 1:171182 .

24. Lohdi, M. A. K. 1976. Role of a1lelopathy as expressed by dominating trees in a lowland forest in controlling the productivity and pattern of herbaceous growth. Amer. J. Bot. $63: 1-8$.

25. Maguire, J. D. 1962. Speed of germination - aid in se1ection and evaluation for seedling emergence and vigor. Crop Sci. 2:176-177.

26. Massey, A. B. 1925. Antagonism of the walnuts (Jug1ans nigra L. and $\mathrm{J}$. cinerea L.) in certain plant associations. Phytopathology 15:773-784. 
27. McCa1la, T. M. and F. L. Duley. 1949. Stubble mulch studies. III. Influence of soil microorganisms and crop residues on the germination, growth and direction of root growth of corn seedlings. Proc. Soil Sci. Soc. Amer. 14:196-199.

28. Meiklejohn, J. 1962. Microbiology of the nitrogen cycle in some Ghana soils. Emp. J. of Exper. Agric. 30:115-126.

29. Meiklejohn, J. 1968. Numbers of nitrifying bacteria in some Rhodesian soils under natural grass and improved pastures. J. of Appl. Eco1. 5:291-300.

30. Molina, J. A. E. and A. D. Rovira. 1964. The influence of plant roots on autotrophic nitrifying bacteria. Can. J. Microbiol. 10:249-257.

31. Molisch, H. 1937. "Der Einfluss einer Pflanze auf die andere - Allelopathie." Fischer, Jena. cited in Rice, E. L. 1974. Allelopathy. Academic Press, New York. $353 \mathrm{pp}$.

32. Moore, D. R. E. and J. S. Waid. 1971. The influence of washings of living roots on nitrification. Soil Biol. Biochem. 3:69-83.

33. Muller, C. H. 1965. Inhibitory terpenes volatilized from Salvia shrubs. Bull. Torrey Bot. Club 92:38-45.

34. Muller, C. H. 1966. The role of chemical inhibition (allelopathy) in vegetational composition. Bull. Torrey Bot. Club 93:332-351.

35. Muller, C. H. and R. Del Moral. 1966. Soil toxicity induced by terpenes from Salvia leucophylla. Bull. Torrey Bot. Club 93:130-137.

36. Muller, C. H., W. H. Muller and B. L. Haines. 1964. Volatile growth inhibitors produced by aromatic shrubs. Science 143:471-473.

37. Muller, W. H. 1965. Volatile materials produced by Salvia leucophylla: effects on seedling growth and soil bacteria. Botan. Gaz. 126:195-200.

38. Muller, W. H. and C. H. Muller. 1964. Volatile growth inhibitors produced by Salvia species. Bull. Torrey Bot. C1ub 91:327-330.

39. Oh, S. D. and R. F. Carlson. 1976. Water soluble extracts from peach plant parts and their affect on growth of seedlings of peach, apple and bean. J. Amer. Soc. Hort. Sci. 101: $54-57$. 
40. Patrick, Z. A. 1955. The peach replant problem in Ontario: toxic substances from microbial decomposition products of peach root residues. Can. J. Bot. 33:461-486.

41. Patrick, Z. A. and L. W. Koch. 1958. Inhibition of respiration, germination and growth by substances arising during the decomposition of certain p1ant residues in the soil. Can. J. Bot. 36:621-647.

42. Rice, E. L. 1964. Inhibition of nitrogen-fixing and nitrifying bacteria by seed plants (I). Ecology 45: $824-837$.

43. Rice, E. L. 1974. In Allelopathy. Academic Press, New York. $353 \mathrm{pp}$.

44. Rice, E. L. 1979. Allelopathy-an update. Bot. Rev. 45:15-109.

- 45. Singh, S. P. 1968. Presence of a growth inhibitor in the tubers of nutgrass (Cyperus rotundus L.). Ind. Acad. Sci. $67: 18-23$.

- 46. Smith, E. V. and G. L. Fick. 1937. Nutgrass eradication studies: I. Relation of the life history of nutgrass, Cyperus rotundus L., to possible methods of control. Amer. Soc. Agron. J. 29:1007-1013.

47. Stee1, R. G. D. and J. H. Torrie. 1960. In Principles and procedures of statistics. McGraw-Hill Book Co., Inc. New York.

4 48. Steenhagen, D. A. and R. L. Zimdah1. 1979. A11e1opathy of leafy spurge. (Euphorbia esula). Weed Sci. 27:1-3.

49. Sti11, S. M., M. A. Dirr and J. B. Gartner. 1976. Phytotoxic effects of several barkextracts on mung bean and cucumber growth. J. Amer. Soc. Hort. Sci. 101:34-37.

450. Stoller, E. W. 1973. Effect of minimum soil temperature on differential distribution of Cyperus rotundus and C.

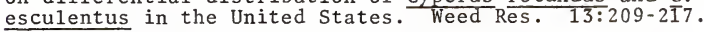

51. Stotzky, G. and S. Schenck. 1976. Observations on organic volatiles from germinating seeds and seedlings. Amer. J. Bot. 63:798-805.

52. Teo, C. K. H., R. K. Nishimoto and C. S. Tang. 1974. Bud inhibition of Cyperus rotundus L. tubers by inhibitor or abscisic acid and the reversal of these effects by n-6-benzy1 adenine. Weed Res. 14:173-179. 
- 53. Teo, C. K. H., B. H. Zandstra and R. K. Nishimoto. 1973. Purple nutsedge (Cyperus rotundus): its biology and control. Proc. Asian-Pacific Weed Sci. Soc. 4th :184-190.

54. Theron, J. J. 1951. The influence of plants on the mineralization of nitrogen and the maintenance of organic matter in the soil. J. Agric. Sci. 41:289-296.

-55. Thullen, R. J. and P. E. Keeley. 1979. Seed production and germination in Cyperus esculentus and $\underline{C}$. rotundus. Weed Sci. 27:502-505.

56. Tisda1e, S. L. and W. L. Ne1son. 1970. In Soil fertility and fertilizers. 2nd ed. Macmillan Co., CollierMacmillan Canada, Ltd., Toronto, Ontario.

57. Torrey, J. G. 1976. Root hormones and plant growth. Ann. Rev. P1. Physiol. 27:435-459.

- 58. William, R. D. 1976. Purple nutsedge: tropical scourge. HortScience 11:357-364.

-59. William, R. D. and G. F. Warren. 1975. Competition between purple nutsedge and vegetables. Weed Sci. $23: 317-323$.

460. Wills, G. D. 1977. Nutsedge deals misery to cotton growers. Weeds Today 8:16-17.

61. Wilson, R. E. and E. L. Rice. 1968. Allelopathy as expressed by Helianthus annuus and its role in old-field succession. Bull. Torrey Bot. Club 95:432-448. 


\section{BIOGRAPHICAL SKETCH}

James Preston Gilreath was born on September 20, 1947, in Greenville, South Carolina, where he received his primary and secondary education. He attended Clemson University from June 1965, to July 1966, majoring in chemical engineering. After leaving Clemson, he served in the United States Army Reserves and worked for a paint manufacturing firm in Greenville, South Carolina. In August 1970, he re-enrolled at Clemson University and was awarded the degree of Bachelor of Science in Plant Sciences-Agronomy in May 1974. In May 1976, he received the degree of Master of Science in Horticulture from Clemson University. He entered the University of Florida in June 1976, and was awarded the degree of Doctor of Philosophy in March 1981, with a major in horticultural science (vegetable crops).

He was honorably discharged from the United States Army Reserves in June 1972 .

He married Phyllis Anne Robinson of Knoxville, Tennessee, on June 21, 1975. 
I certify that I have read this study and that in my opinion it conforms to acceptable standards of scholarly presentation and is fully adequate, in scope and quality, as a dissertation for the degree of Doctor of Philosophy.

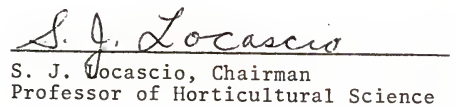

I certify that I have read this study and that in my opinion it conforms to acceptable standards of scholarly presentation and is fully adequate, in scope and quality, as a dissertation for the degree of Doctor of Philosophy.

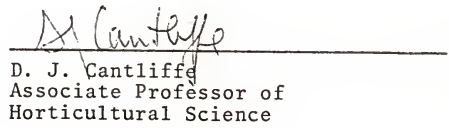

I certify that I have read this study and that in my opinion it conforms to acceptable standards of scholarly presentation and is fully adequate, in scope and quality, as a dissertation for the degree of Doctor of Philosophy.

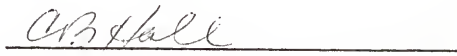

C. B. Hall

Professor of Horticultural Science

I certify that I have read this study and that in my opinion it conforms to acceptable standards of scholarly presentation and is fully adequate, in scope and quality, as a dissertation for the degree of Doctor of Philosophy.

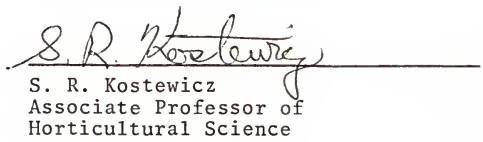


I certify that I have read this study and that in my opinion it conforms to acceptable standards of scholarly presentation and is fully adequate, in scope and quality, as a dissertation for the degree of Doctor of Philosophy.

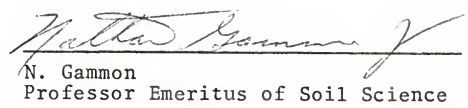

I certify that I have read this study and that in my opinion it conforms to acceptable standards of scholarly presentation and is fully adequate, in scope and quality, as a dissertation for the degree of Doctor of Philosophy.

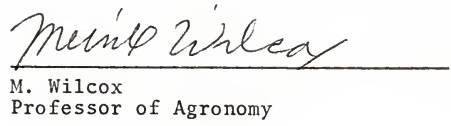

This dissertation was submitted to the Graduate Faculty of the College of Agriculture and to the Graduate Council, and was accepted as partial fulfillment of the requirements for the degree of Doctor of Philosophy.

March, 1981

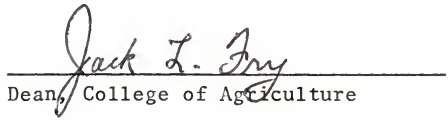

Dean for Graduate Studies and Research 